Monika Baumgartner

\title{
DIE ENTWICKLUNGSTENDENZEN \\ IN DER WESTDEUTSCHEN LANDWIRTSCHAFT
}

Ein einführender Bericht unter Berücksichtigung der ökonomischen Lage der Bauern und des Verhältnisses von Landwirtschaft und Industrie.

\section{Einleitung}

In der Landwirtschaft der EWG-Länder ist ein ständiger Rückgang der Erwerbstätigen zu beobachten. Dies trifft selbst dort zu, wo bereits ein relativ niedriger Anteil von Beschäftigten in der Landwirtschaft vorhanden ist, wie z. B. in Belgien und den Niederlanden. Außerdem verringert sich die Anzahl der landwirtschaftlichen Betriebe in großem Umfang. Allein in der BRD sind es in jedem Jahr durchschnittlich 29900. Bei diesem Prozeß handelt es sich in erster Linie um die Verwandlung von selbständigen Produzenten in Lohnarbeiter, also um die Trennung der Bauern von ihren Produktionsmitteln. Darauf deutet auch die hohe Anzahl landwirtschaftlicher Zuerwerbs- und Nebenerwerbsbetriebe hin, die nur Ausdruck für den Übergang des bäuerlichen Produzenten zum industriellen Lohnarbeiter sind. Die Tatsache, daß es Tendenzen zur Durchsetzung der kapitalistischen Produktionsweise in der Landwirtschaft der EWG-Länder selbst gibt, macht den Charakter dieses Prozesses deutlicher. Es handelt sich um die letzten Stufen jener ursprünglichen Akkumulation des Kapitals auf der einen und der Lohnarbeiter auf der anderen Seite, deren klassische Form Marx am Beispiel Englands darstellte.

War die ursprüngliche Akkumulation in ihrer klassischen Form die Voraussetzung zur kapitalistischen Produktionsweise in gesellschaftlichem Maßstab, so ist der heute in der Landwirtschaft zu beobachtende Prozeß als ein Mittel zu ihrer weiteren Entfaltung zu betrachten. Außerdem haben sich mit der Etablierung der bürgerlichen Gesellschaft notwendigerweise die Methoden zur Enteignung der selbständigen Produzenten gewandelt. Ỏkonomische Veränderungen vollziehen sich nicht mehr durch unmittelbare Gewalt, wie es in England jedenfalls in den ersten Jahrhunderten fast ausschließlich der Fall war. Der größte Teil der Bauern wird heute durch die Konkurrenz in einer teilweise schon monopolistisch entwickelten kapitalistischen Gesellschaft 
proletarisiert; seit der gemeinsamen Agrarpolitik der EWG-Länder sind auch bewußte Maßnahmen zur Förderung des Proletarisierungsprozesses festzustellen, z. B. Prämien für Landabgabe, Einkommensausgleichszahlungen usw. Der vorliegende Aufsatz soll einerseits in die allgemeine Problematik des Agrarsektors in einer fortgeschrittenen kapitalistischen Gesellschaft einführen und andererseits die speziellen Probleme der westdeutschen Landwirtschaft aufzeigen. Er umfaßt folgende Schwerpunkte:

1. Die Veränderungen in der Landwirtschaft, die mit der gesellschaftlichen Entfaltung der kapitalistischen Produktionsweise eintreten.

2. Der Versuch einer Bestimmung der vorherrschenden Form, unter der sich sich die landwirtschaftliche Produktion in der BRD vollzieht, und ihre Auswirkungen auf die ökonomische Lage der Bauern.

3. Die Darstellung der besonderen Formen, in denen sich die kapitalistische Produktionsweise in der Landwirtschaft der BRD durchsetzt.

In der bürgerlichen Statistik werden die landwirtschaftlichen Betriebe nur nach ganz äußerlichen Erscheinungen, wie z. B. nach der Größe der landwirtschaftlichen Nutzfläche (LN) differenziert. Deshalb war es nicht möglich festzustelien, inwieweit sich der in Westdeutschland typische traditionelle Bauernbetrieb, auf dem der Bauer Arbeiter und Produktionsmittelbesitzer ist, direkt in einen kapitalistischen Betrieb verwandelt, auf dem der Bauer unter Umständen auch noch arbeitet, in erster Linie aber Produktionsmittelbesitzer ist und Lohnarbeiter anwendet. Diese Form der kapitalistisch betriebenen Landwirtschaft gibt es in der BRD auch; sie hat aber offenbar gegenüber anderen Formen einen geringen Stellenwert, denn die absolute Zahl der landwirtschaftlichen Lohnarbeiter ist niedrig (1969 betrug sie 165000 ) und hat außerdem eine rückläufige Tendenz. Aufgrund der Unmöglichkeit einer genaueren Differenzierung der landwirtschaftlichen Betriebe in dieser Hinsicht, ergibt sich die Schwierigkeit, daß oft von ,der Landwirtschaft' und ,den Bauern' gesprochen werden muß. Der Leser sollte dabei im Hinterkopf haben, $\mathrm{da} ß$ darunter einerseits auch der Teil der Betriebe fällt, in denen sich das kapitalistische Produktionsverhältnis in der gerade beschriebenen Form hergestellt hat und wo der Bauer ein Kleinkapitalist ist und andererseits auch die wenigen Großbetriebe feudalistischen Ursprungs (z. B. Fürstenberg usw.). Für eine genauere Analyse, die zur Strategiebestimmung im Agrarsektor beitragen soll, wäre es unabdingbar, gerade diese kapitalistischen landwirtschaftlichen Betriebe zu erfassen und ihre Entwicklungstendenzen zu untersuchen.

$\mathrm{Da}$ es sich hier nur um einen einführenden Bericht handelt, konnte auf den wichtigen Komplex der BRD- und der EWG-Agrarpolitik, der staatlichen Eingriffe in die Landwirtschaft auf den verschiedenen Ebenen nicht eingegangen werden. Gleiches gilt für die politische Organisation der westdeutschen Bauern, den „Deutschen Bauernverband“, seine Struktur, seine personelle Zusammensetzung und seine Politik. Beides wären wichtige Aspekte einer weitergehenden Analyse. 


\section{Die Transformation der.Landwirtschaft durch die Entfaltung der kapita- listischen Produktionsweise}

Die historische Aufgabe, die der Kapitalismus hinsichtlich der Landwirtschaft erfüllt hat, ist die Vergesellschaftung der landwirtschaftlichen Produktion. Lenin schreibt dazu: „In der Tat, daß sich die Landwirtschaft aus einem Privileg des obersten oder einer Form des untersten Standes in eine gewöhnliche kommerziell-industrielle Beschäftigung verwandelt, daß das Arbeitsprodukt des Landwirts auf dem Markt einer gesellschaftlichen Kontrolle unterworfen wird; daß sich die einförmige Routine der Landwirtschaft in die technisch umgestalteten und mannigfaltigen Formen der warenproduzierenden Landwirtschaft verwandelt, daß die lokale Abgeschlossenheit und Zersplitterung der kleinen Landwirte beseitigt werden, daß die mannigfachen Formen der Schuldknechtschaft und der persönlichen Abhängigkeit durch unpersönliche Abmachungen über Kauf und Verkauf der Arbeitskraft verdrängt werden - alles das sind Kettenglieder eines Prozesses, der die landwirtschaftliche Arbeit vergesellschaftet..." 5 )

Die einzelnen Elemente der kapitalistischen Form der Vergesellschaftung landwirtschaftlicher Produktion sind die Konstituierung der Warenproduktion, die Arbeitsteilung zwischen der Landwirtschaft und anderen Wirtschaftszweigen und innerhalb der Landwirtschaft selbst und die Umwälzung der land-" wirtschaftlichen Produktionsmethoden. Hinzu kommt die Herstellung des kapitalistischen Produktioṇsverhältnisses in der Landwirtschaft, das bedeutungsvoll für die Vergesellschaftung der Arbeitsprozesse, die in der bäuerlichen Landwirtschaft überwiegend von den Produzenten vereinzelt und isoliert durchgeführt werden. Für die BRD ist zu sagen, daß sich die Warenproduktion in der Landwirtschaft voll durchgesetzt hat, ohne daß sich in diesem Bereich der Produktion das kapitalistische Produktionsverhältnis herstellte.

a) Die Durchsetzung der Warenproduktion in der Landwirtschaft.

Mit der Auflösung der feudalen Bindungen entwickelt sich neben dem Grundverhältnis Lohnarbeit-Kapital die Befreiung des Bauern gegenüber dem Grundherrn. Das Mehrprodukt des Bauern wird nicht mehr in Abgaben (Produktenrente) und Leistungen (Arbeitsrente) gebunden, sondern seine Produkte gelangen zum Austausch auf den Markt. Wenn auch schon zur Feu-

5) Lenin, W. I., Die Entwicklung des Kapitalismus in Rußland, in: Werke Bd.3, Berlin DDR 1963, S. $320 \mathrm{f}$, 
dalzeit der teilweise Verkauf von bäuerlichem Mehrprodukt auf dem Markt nachweisbar ist ${ }^{6}$ ), so hat dieser doch einen ganz anderen Charakter, denn es handelt sich nur um eine Verwandlung des naturalen Mehrprodukts in Geld (Geldrente), das dem Grundherrn oder Landesherrn abzuliefern ist. Das Charakteristische der nichtkapitalistischen Warenproduktion ist aber, daß der Produzent Eigentümer des für seine Ware eingetauschten Äquivalents ist. Mit zunehmender Arbeitsteilung verlieren die auf den Markt gebrachten Produkte den Charakter von Überschüssen, die über die zur Reproduktion der Bauernfamilie notwendigen Lebensmittel hinaus auf dem Bauernhof selbst produziert wurden. Das landwirtschaftliche Produkt wird zur Ware, die produziert wird, um auf dem Markt gegen das allgemeine Äquivalent - Geld - ausgetauscht zu werden, mit dem dann Subsistenzmittel für die Bauernfamilie und Produktionsmittel gekauft werden.

Dieser Übergang von der Subsistenzwirtschaft zur Warenproduktion kann sogar noch in der Landwirtschaft der Gegenwart sehr gut verfolgt werden. Er spiegelt sich wider in dem ständigen Rückgang des Eigenverbrauchs der in der Landwirtschaft Tätigen an den landwirtschaftlichen Produkten. „Wurden im Durchschnitt der Jahre 1935/38 76,4\% und $195077,3 \%$ der pflanzlichen und tierischen Produktion auf dem Markt abgesetzt, so 1960/61 86,5\%. Entsprechend ging der Anteil des Eigenverbrauchs zurück. Der Selbstversorgeranteil der Landwirtschaft am Verbrauch von Getreide in Westdeutschland insgesamt hat sich gegenüber der Vorkriegszeit um die Hälfte verringert. Der Anteil der Hausschlaçhtungen an den Gesamtschlachtungen betrug in der Vorkriegszeit 40\%, Anfang der sechziger Jahre nur noch $20 \%$. " ${ }^{7}$ ) Nach Angaben des Grünen Berichts 1970 betrug der Eigenverbrauch am Produktionswert im Wirtschaftsjahr 1968/69 nur noch 9,3\%. ${ }^{8}$ )

Die notwendige Kehrseite dieses Prozesses ist die wachsende Abhängigkeit vom kapitalistischen Markt, in die der Bauer als nichtkapitalistischer Warenproduzent gerät. Für den unmittelbaren Produzenten hat das schwerwiegende Folgen, denn in der warenproduzierenden Landwirtschaft vollzieht sich die Produktion ebenso krisenhaft wie in anderen Bereichen. ${ }^{9}$ ) Die Folgen einer anarchischen Produktion für einen dem einzelnen Warenproduzenten unbekannten Markt verschärfen sich mit zunehmender Integration des nationalen Agrarmarktes in den Weltmarkt. Ein Indiz dafür ist die Tatsache, daß die erste Weltagrarkrise in die Zeit fällt, in der der Weltagrarmarkt beginnt, sich umfassend zu entfalten (letztes Viertel des 19. Jahrhunderts). ${ }^{10}$ ) Die beson-

6) Vgl: Saalfeld, Dietrich, Bauernwirtschaft und Gutsbetrieb in der vorindustriellen Zeit, Stuttgart 1960, S. 85,

7) Gündel, R., u. a., Zur Theorie des staatsmonopolistischen Kapitalismus, Berlin DDR 1967, S. 158,

8) $\mathrm{Vgl}$. Bericht der Bundesregierung über die Lage der Landwirtschaft und Maßnahmen der Bundesregierung (Grüner Bericht) 1970. Drucksache VI/372 des Deutschen Bundestags, S. 58/59,

9) Vgl. Lenin, Die Entwicklung..., a.a. O., S. 317,

10) Vgl. Gündel, Zur Theorie..., a. a. O., S. 168, 
dere Abhängigkeit des westdeutschen Agrarmarkts vom Weltagrarmarkt haben Gündel u. a. in "Zur Theorie des staatsmonopolistischen Kapitalismus“ nachgewiesen. ${ }^{11}$ )

b) Die Ausgliederung von Produktions- und Zirkulationsfunktionen aus der Landwirtschaft.

Die Verallgemeinerung der kapitalistischen Produktionsweise bringt eine Beschleunigung der Arbeitsteilung mit sich. In der Landwirtschaft findet dieser Prozeß Ausdruck in der Ausgliederung von Produktions- und Zirkulationsfunktionen.

"In den gesellschaftlichen Zuständen, die vor der Unterordnung der Landwirtschaft unter den Kapitalismus herrschten, produzierte der Bauer seine Produktionsmittel im wesentlichen selbst; die Herstellung von Energie, Zugkräften, Düngemitteln, Futtermitteln, Saatgut usw. war Teil seines eigenen Arbeitsprozesses. Auch notwendige Bauten wurden hauptsächlich von inm selbständig, eventuell mit Hilfe von Nachbarn, ausgeführt. Der Kapitalismus hat hier das Bild gründlich verändert ..." ${ }^{13}$ )

Die Ausgliederung betrifft auf der Produktionsseite die Produktion von Produktionsmitteln und die Weiterverarbeitung von agrarischen Rohstoffen, auf der Zirkulationsseite die Verkaufsfunktion. ${ }^{14}$ ) Als Indikatoren für die Ausgliederung der Produktion von Produktionsmitteln nennen die Autoren von "Zur Theorie des staatsmonopolistischen Kapitalismus" das raschere Ansteigen der Betriebsausgaben gegenüber dem Produktionswert der Landwirtschaft und den steigenden Anteil der Ausgaben für Produktionsmittel an den Verkaufserlösen. ${ }^{15}$ ) Als ein aktuelles Beispiel für den Prozeß der Ausgliederung kann die Entwicklung der Futtermittelindustrie in der BRD genannt werden. Sie wurde vorangetrieben durch die rasche Zunahme der tierischen Veredelungsproduktion und weist auf die relative Abnahme der Bedeutung der landwirtschaftlichen Futtermittelerzeugung hin. Von 1954 bis 1968 erhöhte sich die Anzahl der Betriebe der Futtermittelindustrie kontinuierlich von 300 auf 398, die Anzahl der Beschäftigten in diesem Industriezweig von 6600 auf 13000 , der Umsatz von 528 Mio. auf 3,089 Mrd. DM. ${ }^{16}$ )

In der Subsistenzwirtschaft wurden die landwirtschaftlichen Produkte notwendigerweise auf dem Bauernhof selbst konsumreif gemacht. Die Tatsache, $\mathrm{da} \beta$ in der Warenproduktion der größte Teil von innen den Haushalten nicht unmittelbar zugeführt werden kann, sondern einen Prozeß der Aufbereitung

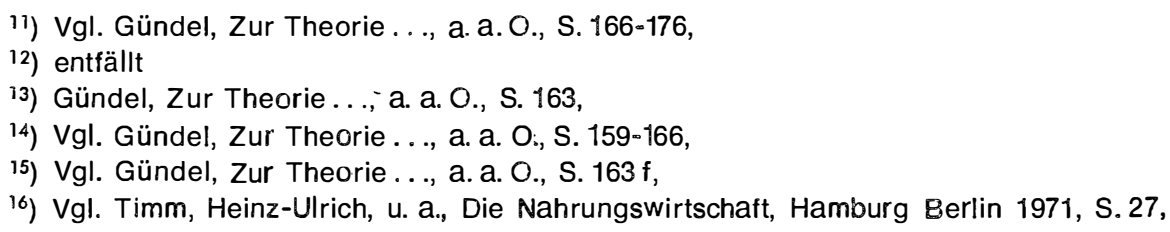


und Verarbeitung durchlaufen muß, zwingt zur Ausgliederung dieser Tätigkeiten aus dem landwirtschaftlichen Betrieb. Dieser Prozeß spiegelt sich wider in der zunehmenden Bedeutung der Ernährungsindustrie. ${ }^{17}$ )

Für die Ausgliederung der Verkaufsfunktion aus der Landwirtschaft ist der Direktabsatz von landwirtschaftlichen Produkten durch den Produzenten ein Indikator. Er macht Z. B. bei Eiern und Speisekartoffeln immer noch etwa die Hälfte des Gesamtumsatzes aus, bei Schweinen und Rindern nur noch etwa ein Drittel, bei Suppenhühnern und Milch etwa ein Fünftel. ${ }^{18}$ ) Diese Angaben beziehen sich nicht nur auf den Absatz des Produzenten an den Konsumenten, sondern erhalten auch den Absatz an Nahrungsmitteleinzelhandel und Nahrungsmittelhandwerk.

Die Landwirtschaft wird durch diesen Prozeß der Ausgliederung ausschließlich auf die Produktion von landwirtschaftlichen Produkten beschränkt, die wiederum zum allergrößten Teil Halbfabrikate sind, die der weiterverarbeitenden Industrie als agrarische Rohstoffe dienen. Durch diese Beschränkung ergibt sich eine Arbeitsteilung (Spezialisierung) innerhalb der Landwirtschaft selbst. Die Eigenart der Spezialisierung in der Landwirtschaft gegenüber der der Industrie wird durch folgendes Zitat aus dem Buch von Gündel u. a. klar: „Daraus ergibt sich, daß die Spezialisierung in der Landwirtschaft ..., sich in der Form vollzieht, daß in der einen Gegend (bzw. in dem einen Betrieb) beispielsweise Getreide für den Markt produziert und zum Hauptprodukt wird, während die anderen Produkte, die in dieser Gegend bzw. Betrieb produziert werden, diesem Hauptprodukt untergeordnet sind und nur in geringem Maße oder gar nicht auf dem Markt erscheinen. Dagegen wird in einer anderen Gegend (bzw. in einem anderen Betrieb) das Vieh bzw. eine bestimmte Viehart zum Hauptmarktprodukt, während das Getreide hauptsächlich zu Futterzwecken verwendet und auch die übrigen Produktionseinrichtungen den Bedürfnissen der Hauptproduktion weitgehend angepaßt und untergeordnet werden." 19 ) Die Besonderheiten der Spezialisierung haben sowohl natürliche (Fruchtwechsel, Abfälle der Bodenproduktion, die durch Viehwirtschaft verwertet werden können, usw.) als auch gesellschaftlich-historische Ursachen (Zersplitterung der landwirtschaftlichen Produzenten und geringere Größe der bäuerlichen Betriebe).

Die Kehrseite, dieses Ausgliederungsprozesses besteht darin, da $B$ industrielles Kapital, permanent auf der Suche nach profitablen Anlagesphären, in die ausgegliederten Bereiche fließt. Welche Auswirkungen das auf den unmittelbaren Produzenten der agrarischen Rohstoffe - also den Bauern - hat, wird später zu untersuchen sein.

17) Vgl. Thimm, Die Nahrungswirtschaft, a. a. O., S. $100 \mathrm{ff}$,

18) Vgl. Oppen, Matthias von, Möglichkeiten und Grenzen der Anwendung vertraglicher Regelungen beim Absatz landwirtschaftlicher Produkte, Braunschweig-Völkenrode 1968, S. 29. Aus dem Text geht keine Jahreszahl für den Direktabsatz hervor, das übrige statistische Material der Untersuchung bezieht sich auf den Anfang der 60 er Jahre. Es ist anzunehmen, daß der Direktabsatz inzwischen weiter gesunken ist. 19) Gündel, Zur Theorie..., a. a. O., S. 160 f, 
c.) Die Umwälzung der Produktionsmethoden in der Landwirtschaft.

Lenin beschreibt in "Die Entwicklung des Kapitalismus in Rußland“ (1899) sehr detailliert die Auswirkungen, die die sich durchsetzende kapitalistische Produktionsweise in Rußland auf die Landwirtschaft ausübt. Er betont $u$. a. die hervorragende historische Leistung des Kapitalismus, der die Möglichkeit schafft, durch Anwendung der Technik und chemischer Produkte die Landwirtschaft aus ihrer Stagnation herauszureißen und ihre Produktivkräfte zu entfalten. ${ }^{20}$ ) Die drei wichtigsten Methoden, die Produktivkraft der Arbeit in der Landwirtschaft zu steigern, sind die Anwendung der Technik (Mechanisierung), die Anwendung der Agrochemie (z. B. Erhöhung der Fruchtbarkeit des Bodens durch künstliche Düngemittel) und die Anwendung der Ergebnisse der biologischen Forschung (Erhöhung der Leistungs- und Ertragsfähigkeit von Tieren und Pflanzen durch Zucht).

Die Steigerung der Produktivkraft der Arbeit durch die Anwendung der Technik in der Landwirtschaft ist ganz offensichtlich, wenn man z. B. die Veränderung der Getreideerzeugung betrachtet, bei der durch die Einführung des Mähdreschers ursprünglich selbständige Arbeitsgänge eingespart bzw. mit anderen zusammengelegt werden, wie z. B. das Dreschen.

Durch die Anwendung der Methoden der Agrochemie und der Biologie haben sich die Ernteerträge pro ha und die tierischen Leistungen erheblich gesteigert. Vergleicht man den mittleren Hektarertrag der Jahre 1957 bis 1961 mit dem der Jahre 1963 bis 1968, so stieg er in der BRD bei Getreide insgesamt von $28,0 \mathrm{dz}$ auf $32,8 \mathrm{dz}$, bei Kartoffeln von $223,9 \mathrm{dz}$ auf $265,9 \mathrm{dz}$, bei Zuckerrüben von 394,1 dz auf 429,6 dz. ${ }^{21}$ ) Der Jahresmilchertrag je Kuh stieg von 1962/63 bis 1968/69 kontinuierlich von $3485 \mathrm{~kg}$ auf $3760 \mathrm{~kg}$. Die Jahreseierleistung je Henne stieg im selben Zeitraum kontinuierlich von 166 auf 211 Stück. ${ }^{22}$ )

Aussagekräftig hinsichtlich der Steigerung der Produktivkraft der Arbeit werden die oben genannten Zahlen nur, wenn man sie im Zusammenhang mit der Veränderung der Zahl der Erwerbstätigen in der Landwirtschaft betrachtet. Nach Angaben des Grünen Berichts 1970 nahm die Zahl der Erwerbstätigen in der Landwirtschaft 1968/69 gegenüber dem Vorjahr um 4\% ab. ${ }^{23}$ ) Demgegenüber erhöhte sich die Nahrungsmittelproduktion (pflanzliche und tierische Produktion) von $1967 / 68$ bis $1968 / 69$ von 58,57 Mio auf 59,83 Mio $t$ Getreideeinheiten (=2\%). ${ }^{24}$ ) „Der starke Rückgang der Arbeitskräfte.... und die Ausweitung der Produktion haben in der Landwirtschaft seit 1960 eine Steigerung der Arbeitsproduktivität der Landwirtschaft um über

20) Vgl. Lenin, Die Entwicklung ..., a. a. O., S. 317 f, vgl. dazu auch: Marx, Karl, Das Kapital, Bd. I, in: Marx Engels Werke (MEW), Bd. 23, Berlin DDR 1969, S. $527 \mathrm{ff}$,

21) Vgl. Grüner Bericht 1970, a. a. O., S. 39,

22) Vgl. Grüner Bericht 1970, a. a. O., S. 195,

23) Vgl. Grüner Bericht 1970, a. a. O., S. 7,

24) Vgl. Grüner Bericht 1970, a. a. O., S. 41, 
$60 \%$ gebracht gegenüber $40 \%$ in den übrigen Wirtschaftsbereichen." ${ }^{25}$ ) „Im Jahre 1949/50 erzeugte eine Arbeitskraft 7,8 t und im Wirtschaftsjahr 1964/65 27,9 t Getreideeinheiten. Das heißt, die Nahrungsmittelproduktion pro Arbeitskraft stieg um $256 \%$." ${ }^{26}$ )

Absolut steigende Nahrungsmittelproduktion bei absolut sinkender Zahl der Erwerbstätigen in der Landwirtschaft zeigen nicht nur eine Steigerung der Produktivkraft der Arbeit an, sondern lassen auch auf eine erhebliche Intensivierung der Arbeit des unmittelbaren Produzenten in der Landwirtschaft schließen. ${ }^{26}{ }_{\mathrm{g}}$ ) $\mathrm{Zu}$ der gewaltigen Produktivitätssteigerung in der Landwirtschaft der BRD bemerken die Autoren vòn „Imperialismus heute": „Aus diesen beachtlichen Ergebnissen darf jedoch nicht geschlußfolgert werden, daß sich die Lage der Hauptmasse der landwirtschaftlichen Produzenten, das heißt der werktätigen Bauern, und ihre Stellung gegenüber dem Monopolkapital wesentlich verbessert oder gar grundlegend gewandelt hat." ${ }^{27}$ )

d) Der Konzentrations- und Zentralisationsprozeß in der Landwirtschaft.

Durch die Expropriation eines Teils der ländlichen Produzenten von ihren Produktionsmitteln und durch die Umwälzung der Produktionsmethoden in der Landwirtschaft ergeben sich auch in diesem Wirtschaftszweig notwendigerweise Tendenzen zur Konzentration und Zentralisation. Marx geht bei der Analyse dieses Prozesses von der kapitalistischen Produktionsweise in der Landwirtschaft aus, wie sie sich in England durchgesetzt hatte. Bergmann gibt in seinem Aufsatz „Die Agrarfrage bei Marx und Engels - und heute" eine kurze Zusammenfassung dieser Analyse: „Ist Marx sich also völlig im klaren, daß der Kapitalismus sich der Agrikultur bemächtigt, wenn auch mit Gradunterschieden, so sieht er doch diesen Prozeß nicht einseitig als eine Vergrößerung der Betriebsflächen." ${ }^{28}$ ) Dies sei nur eine Seite des Prozesses, nämlich die Zentralisation von Boden in weniger Händen (Erweiterung der Produktion durch Betriebsvergrößerung), während die andere Seite die Konzentration von Produktionsmitteln sei ${ }^{29}$ ) (u. U. Betriebsverkleinerung, aber Erweiterung der Produktion durch intensivere Bewirtschaftung des Bodens). ${ }^{30}$ )

25) Grüner Bericht 1970, a. a. O., S. 7,

26) Imperialismus heute, Berlin DDR 51968, S. 306,

26a) So hat z. B. der Ersatz des Pferdegespanns als Transportmittel durch den Traktor die Pausen des Arbeitstages erheblich verkürzt.

27) Imperialismus heute, a. a. O., S. $306 \mathrm{f}$, .

${ }^{28}$ ) Bergmann, Theodor, Die Agrarfrage bei Marx und Engels - und heute, in: Kritik der politischen Ökonomie heute - 100 Jahre ,Kapital', Frankfurt 1968, S. 177,

${ }^{29}$ ) Vgl. Marx, Kapital I, a. a. O., S. 348, Fußnote 18,

30) Bergmann verweist a. a. O. in diesem Zusammenhang auf die Ergebnislosigkeit der sozialdemokratischen Agrardebatte (im wesentlichen geführt zwischen Kautsky, Bernstein und David), die daran scheiterte, daß eine Seite dieses Prozesses, nämlich die Konzentration von Produktionsmitteln, vernachlässigt wurde. 
In den kapitalistischen Ländern, in denen sich eine nichtkapitalistische Produktionsweise in der Landwirtschaft erhalten hat, vollzieht sich dieser Konzentrations- und Zentralisationsprozeß, der keine Konzentration und Zentralisation von Kapital ist, sehr langsam, vor allen Dingen hinsichtlich der Zentralisation des Bodens. So hat sich nach Angaben der Kommission der Europäischen Gemeinschaften z. B. die Durchschnittsfläche der über 1 ha großen Betriebe in der BRD innerhalb von 10 Jahren (etwa im Zeitraum von 1959 bis 1969) um 1 ha erhöht. ${ }^{31}$ ) Auf der Seite der Produktionsmittel ist ein stärkerer Konzentrationsprozeß zu beobachten. Z. B. erhöhte sich der Schlepperbestand in der BRD von 1963 bis 1965 von 1,05 Mio auf 1,16 Mio Stück und der Mähdrescherbestand von 95000 auf 120000 Stück ${ }^{32}$ ), während sich im selben Zeitraum die Anzahl der landwirtschaftlichen Betriebe um rund 75700 verringerte. ${ }^{33}$ ) Die Autoren von "Zur Theorie des staatsmonopolistischen Kapitalismus" stellen zu recht fest, daß trotz der Veränderung der Agrarstruktur und der Abnahme der Erwerbstätigen in der Landwirtschaft der BRD die unmittelbare landwirtschaftliche Produktion im Vergleich zur industriellen außerordentlich gering konzentriert ist. ${ }^{34}$ )

Die speziellen Probleme des Konzentrations- und Zentralisationsprozesses in der Landwirtschaft unter den Bedingungen der Monopolisierung ${ }^{34}$ a) der Industriezweige, die der Landwirtschaft vor- und nachgeschaltet sind, werden in Abschnitt VII. b) dargestellt.

\section{e) Die Veränderung des Produktionsverhältnisses in der Landwirtschaft.}

Wie wir im nächsten Abschnitt sehen werden, dringt mit der Auflösung der feudalen Verhältnisse die kapitalistische Produktionsweise auch in die Landwirtschaft ein. Das kapitalistische Produktionsverhältnis stellt sich entweder her, indem der Grundeigentümer Lohnarbeiter anwendet, oder idem zwischen den Grundeigentümer und den landwirtschaftlichen Lohnarbeiter der kapitalistische Pächter tritt. Dieser wird jetzt der unmittelbare Anwender der

31) Vgl. Die Landwirtschaftsreform in der Gemeinschaft, in: Europäische Dokumentation 1969, Bonn Brüssel 1969, S. 1 ,

32) Vgl. Hrsg. Statistisches Bundesamt, Statistisches Jahrbuch für die Bundesrepublik Deutschland 1968, Stuttgart Mainz 1968, S.60, (internationale Übersichten),

33) Vgl. Bericht der Bundesregierung über die Lage der Landwirtschaft (Grüner Bericht 1965) und Maßnahmen der Bundesregierung (Grüner Plan 1965). Drucksache IV/2990 des Deutschen Bundestags, S. 34; Bericht der Bundesregierung über die Lage der Landwirtschaft (Grüner Bericht 1966) und Maßnahmen der Bundesregierung (Grüner Plan 1966). Drucksache V/255 des Deutschen Bundestags, S. 37,

34) Vgl. Gündel, Zur Theorie..., a. a. O., S. 182 f,

34a) Wenn ich im folgenden abgekürzt von Monopolkapital oder monopolisiertem Kapital spreche, so ist darunter immer Kapital zu verstehen, das sich trotz seiner hohen Konzentration und Zentralisation als konkurrierendes verhalten muß, was sich spätestens auf dem Weltmarkt zeigt. Vgl. zu diesem Problem Neusüß/Blanke/Altvater, Kapitalistischer Weltmarkt und Weltwährungskrise, in: Probleme des Klassenkampfs, Erlangen, Heft 1/1971. 
Lohnarbeiter, während der Grundeigentümer vom Pächter eine Grundrente bezieht. ${ }^{35}$ ) (Typische Form der kapitalistischen Landwirtschaft in England im 18./19. Jahrhundert). Daneben entsteht vorwiegend in Kontinentaleuropa und Japan mit unterschiedlicher Verbreitung die bâuerliche Landwirtschaft, bei der die Bauernfamilie mit eigenen Produktionsmitteln für den Markt produziert. Knechte und Mägde, soweit sie als fremde Arbeitskräfte auf diesen Bauernhöfen existieren, sind nicht mit Lohnarbeitern zu vergleichen. Dies Abhängigkeitsverhältnis entspricht dem der feudalen Produktionsweise, etwa dem Verhältnis Meister - Geselle im handwerklichen Zunftbetrieb, wo die fremde Arbeitskraft integraler Bestandteil der Familie des Meisters war.

In den kapitalistischen Ländern, in denen sich die bäuerliche Landwirtschaft bis heute erhalten hat, sind besondere Tendenzen zur Veränderung des Produktionsverhältnisses festzustellen. Sie stellen sich in der BRD dar.

1. in der Kapitalisierung einzelner Produktionszweige der Landwirtschaft, in die industrielles Kapital hineinfließt und

2. in der ,vertikalen Integration".

Diese beiden Formen der Veränderung des Produktionsverhältnisses in der Landwirtschaft werden in Abschnitt VII. über die Entwicklungstendenzen in der Landwirtschaft der BRD untersucht.

Die kapitalistische Produktionsweise kann sich noch auf einem anderen Weg in der Landwirtschaft durchsetzen. Er besteht darin, daß sich durch Konkurrenz der bäuerlichen Betriebe untereinander der traditionelle Bauernbetrieb in einen kapitalistischen verwandelt, der Bauer also Lohnarbeiter anwendet. Die Schwierigkeiten bei der Untersuchung dieser Form der kapitalistischen Landwirtschaft und die Vermutung, daß dies nicht die herrschende Form ist, in der sich die kapitalistische Produktionsweise in der Landwirtschaft durchsetzt, wurden bereits in der Einleitung dargelegt. In seinem Aufsatz „Zur Bauernfrage in Westdeutschland" schreibt Poppinga zu diesem Problem folgendes: „Die absolute Zahl der kapitalistischen Bauernbetriebe nimmt laufend $a b .$. Der Kapitalismus setzt sich in der Landwirtschaft der Bundesrepublik nicht in erster Linie dadurch durch, daß ein Teil der landwirtschaftlichen Betriebe den anderen niederkonkurriert, sondern durch Übernahme ganzer Bereiche bisher bäuerlicher Produktion durch das industrielle Kapital.“ ${ }^{35}$ a) Aber auch hier kann empirisch nicht eindeutig belegt werden, wie groß der Anteil dieser kapitalistischen Bauernbetriebe an allen landwirtschaftlichen Betrieben in der BRD ist und deshalb kann auch ihre Abnahme nicht klar nachgewiesen werden.

Zur näheren Bestimmung der vorherrschenden Form, unter der sich die landwirtschaftliche Produktion in der BRD vollzieht, folgt im nächsten Abschnitt eine Darstellung der historischen:.Entwicklung der Agrarstruktur in Westdeutschland.

35) Vgl. Marx, Karl, Das Kapital, Bd. III, in: MEW Bd.25, Berlin DDR 1968, S. 631,

35a) Poppinga, Onna-Hans, Zur Bauernfrage in Westdeutschland, Teil I-III, in: links, Nr. 27, 28/1971, Nr. 29/1972, Offenbach, hier: Nr. 29/.1972, S. 19 f. 


\section{Die historische Entwicklung der bäuerlichen Agrarstruktur der BRD.}

Legt man die Kriterien der Bodenreform in der Sowjetischen Besatzungszone nach dem Zweiten Weltkrieg zugrunde, bei der u. a. der Großgrundbesitz über 100 ha enteignet wurde, so ergibt sich für die BRD folgendes Verhältnis zwischen Großgrundbesitz und bäuerlichen Wirtschaften: 1960 entfielen in der BRD rd. 2600 der rd. 1,6 Mio landwirtschaftlichen Betriebe auf die Größenklasse von über 100 ha. Sie bewirtschafteten 450000 ha der rd. 13,1 Mio ha landwirtschaftlichen Nutzfläche (LN). ${ }^{36}$ ) Der zahlenmäßige Anteil dieser Betriebe des Großgrundbesitzes und die auf sie entfallende $L N$ sind also so gering, daß man die Agrarstruktur in der BRD als bäuerliche bezeichnen kann.

Im folgenden sollen kurz die historischen Gründe skizziert werden, die zu unterschiedlichen Agrarstrukturen in Westdeutschland einerseits und in den Gebieten östlich der Elbe (Mecklenburg, Pommern, Ostpreußen und Brandenburg) andererseits führten.

Der wesentliche Unterschied zwischen westdeutscher und ostdeutscher Grundherrschaft entsteht mit der Ostkolonisation, da die Hofländereien der Ritter in diesem Gebiet erheblich größer sind als in dem bereits besiedelten und kultivierten Gebiet Westdeutschlands. ${ }^{37}$ ) Während im Verlauf der geschichtlichen Entwicklung in Westdeutschland am Institut der Grundherrschaft festgehalten wird, bei der der Grundherr seinen Anspruch auf das Mehrprodukt in Form von Abgaben und Diensten aus der Weiterverleihung des Landes an Bauern, die es selbst bewirtschaften, herleitet, bildet sich in Ostdeutschland die Gutsherrschaft heraus, die im Eigenbetrieb der Wirtschaft durch den adeligen Besitzer und den Spann- und Handdiensten seiner Hintersassen besteht. ${ }^{38}$ )

Für die Erweiterung des gutsherrlichen Besitzes boten sich in Ostdeutschland vielfältige Möglichkeiten, die in Westdeutschland nicht gegeben waren. Der Wirtschaftshistoriker Treue nennt als wichtigste: das Bauernlegen, in Ostdeutschland begünstigt durch das Vorhandensein slavischer Bauern in niedrigerer Rechtsstellung als die deutschen Bauern, und die Rodung und Urbarmachung neuer Ländereien aufgrund der dünnen Besiedlung dieser Gebiete. ${ }^{39}$ )

Während im 16. Jahrhundert in Ostdeutschland der Feudalismus seiner ausgeprägtesten Form zustrebt - mit ungemessener Fron für die Bauern, neuen Leistungen für Adel und Territorialstaaten und neuer Leibeigenschaft -, ent-

36) Vgl. Statistisches Jahrbuch 1968, a. a. O., S. 146,

37) Vgl. Schmidt, Hilde-Lore, Die soziale Lage der Landbevölkerung im 18. Jahrhundert sowie Probleme ihrer Umgestaltung, Diss., Berlin 1965, S. 14,

38) Zur begrifflichen Unterscheidung zwischen Grundherrschaft und Gutsherrschaft siehe Schmidt, Die soziale Lage ..., a. a. O., S. $11 \mathrm{ff}$,

39) Vgl. Treue, Wilhelm, Wirtschafts- und Sozialgeschichte vom 16. bis zum 18. Jahrhundert in: Gebhardt, Bruno, Handbuch der deutschen Geschichte, Bd. II, Stuttgart 81955 , S. $377 \mathrm{f}$, 
wickelt sich in Westdeutschland, insbesondere in Niedersachsen, das Meierrecht. „Das Vordringen der Geldwirtschaft in den ländlichen Bereich bewirkte die Umwandlung der naturalwirtschaftlich ausgerichteten Villikationsverfassung in das bewegliche Institut der Zeitpacht - und unter dem Einfluß der erstarkenden Landesherrschaft bildete sich ein erbliches Nutzungsrecht der Bauern an den für unteilbar erklärten Höfen heraus. Diese günstige - Meierrecht genannte - bäuerliche Rechtsinstitution bestimmte die gesamte Agrarverfassung Niedersachsens in der vorindustriellen Zeit... " ${ }^{40}$ )

Die Tendenzen zur Auflösung der feudalen Verhältnisse in der Landwirtschaft kommen erst zu Beginn des 19. Jahrhunderts voll zum Durchbruch, obwohl sie während des ganzen 18. Jahrhunderts in verschiedenen Gebieten mit unterschiedlichen Ergebnissen bestanden hatten. In Preußen führten sie zu dieser Zeit vor allen Dingen zur Auflösung der alten Dorfgenossenschaften, was einem Entzug des Gemeinbesitzes der Bauern gleichkommt und zu ihrer wirtschaftlichen Schwächung beitrug. ${ }^{41}$ )

In Westdeutschland und in Ostdeutschland nimmt die Auflösung der feudalen Verhältnisse eine unterschiedliche Entwicklung. In den Rheinstaaten werden die von Napoleon hinsichtlich der Landwirtschaft erlassenen Gesetze 1815 wieder aufgehoben, in den südlichen Staaten Westdeutschlands wird nur die Befreiung der Person durchgeführt, unter Beibehaltung der Grund- und Gerichtsherrschaft. Das bedeutet, daß an der Agrarstruktur nichts verändert wurde. Die meisten Bauern verblieben auf den bestehenden Betriebsgrößen. ${ }^{42}$ ) „Ganz anders verlief die Bauernbefreiung im Königreich Preußen. Dort wurde sie ..., bis 1816 umfassend durchgeführt, die persönliche Freiheit verliehen und für den größten Teil des mittleren und großen Bauerntums die Grundentlastung durch Verleihung des Eigentums und Fortfall aller Dienste und Abgaben gegen Entschädigung gesetzlich durchgeführt ('Regulierung') “. ${ }^{43}$ )

Engels beschreibt in seinem Aufsatz „Zur Geschichte der preußischen Bauern" ${ }^{44}$ ), daß diese ,Bauernbefreiung 'den Bauern in zweierlei Hinsicht frei macht. Er bekommt die freie Verfügung über seine Arbeitskraft durch die Abschaffung der feudalen Lasten und er wird frei von seinem wichtigsten Produktionsmittel, dem Boden, denn nur die wenigsten Bauern sind in der Lage, ihre Ablösung durch Zahlung von Geld vom früheren Gutsherrn zu

\footnotetext{
40) Saalfeld, Bauernwirtschaft und Gutsbetrieb ..., a. a. O., S. 15,

41) Vgl. Treue, Wilhelm, Wirtschafts- und Sozialgeschichte Deutschlands im 19. Jahrhundert, in: Gebhardt, Bruno, Handbuch der deutschen Geschichte; Bd. III, Stuttgart 81960, S. $319 \mathrm{f}$,

42) Vgl. Treue, Wirtschafts- und Sozialgeschichte Deutschlands ..., a. a. O., S. 320 f,

43) Treue, Wirtschafts- und Sozialgeschichte Deutschlands..., a. a. O., S. $320 \mathrm{f}$,

44) Vgl. Engels, Friedrich, Zur Geschichte der preußischen Bauern, in: MEW Bd. 21, Berlin DDR 1969,
} 
erkaufen, sondern treten inm ihr Land ab. So werden durch die ,Bauernbefreiung' in Preußen den Gutsherren mit der Erweiterung ihrer Betriebsflächen gleichzeitig die notwendigen Landarbeiter geschaffen.

Treue drückt diese vom Staat durchgesetzte Herstellung des Kapitalverhältnisses in der landwirtschaftlichen Produktion so aus: „Die Bauernbefreiung war zugleich vielfach auch eine Befreiung der Herren, die ihren Gutsbesitz durch Landentschädigung der Bauern, freihändigen Erwerb bzw. Einziehung von ungeschützten Bauernstellen vergrößerten, Arbeitskräfte, technische Reformen und Feldbereinigung erhielten, die für einen modernen Betrieb nötig waren, mit Ablösungsgeldern die Wirtschaft verbesserten, gewerbliche Anlagen - Rübenzuckerfabriken, Schnapsbrennereien usw. - anlegten ... " ${ }^{45}$ )

Marx analysiert den historischen Prozeß der Auflösung der feudalen Verhältnisse in der Landwirtschaft - nachdem er die Kategorien Arbeitsrente, Produktenrente, Geldrente entwickelt hat - folgendermaßen: „In ihrer weiteren Entwicklung muß die Geldrente führen - von allen Zwischenformen abgesehen, wie z. B. von der des kleinbäuerlichen Pächters - entweder zur Verwandlung des Bodens in freies Bauerneigentum oder zur Form der kapitalistischen Produktionsweise, zur Rente, die der kapitalistische Pächter zahlt.“ (Eine Form, die zur Voraussetzung hat, daß der Grundbesitzer die Landwirtschaft nicht im Eigenbetrieb führt. „Mit Geldrente verwandelt sich notwendig das traditionellen gewohnheitsrechtliche Verhältnis zwischen den, einen Teil des Bodens besitzenden und bearbeitenden, Untersassen und dem Grundeigentümer in ein kontraktliches, nach festen Regeln des positiven Gesetzes bestimmtes, reines Geldverhältnis. Der bebauende Besitzer wird daher der Sache noch zum bloßen Pächter. Diese Verwandlung wird einerseits, unter sonst geeigneten allgemeinen Produktionsverhältnissen, dazu benutzt, die alten bäuerlichen Besitzer nach und nach zu expropriieren und an ihre Stelle einen kapitalistischen Pächter zu setzen; andererseits führt sie zum Loskauf des bisherigen Besitzers von seiner Rentenpflichtigkeit und zu seiner Verwandlung in einen unabhängigen Bauer, mit vollem Eigentum an dem von inm bestellten Boden. Die Verwandlung von Naturalrente in Geldrente wird ferner nicht nur notwendig begleitet, sondern selbst antizipiert durch Bildung einer Klasse besitzloser und für Geld sich verdingender Tagelöhner." ${ }^{46}$ )

Zusammenfassend kann gesagt werden, daß sich mit der Verallgemeinerung der kapitalistischen Produktionsweise kapitalistische Verhältnisse in der Landwirtschaft Ostdeutschland herausbildeten, wenn auch nicht in der klassischen Form, wie Marx sie für England beschreibt.

In Westdeutschland wurden die feudalen Bindungen in der Landwirtschaft zwar sukzessive abgebaut, aber die Agrarstruktur blieb davon im großen und ganzen unberührt. Es entstand der unabhängige Bauer, der Eigentümer

45) Treue, Wirtschafts- und Sozialgeschichte Deutschlands ..., a. a. O., S. 323 f,

46) Marx, Kapital III, a. a. O., S. 806 \% 
seines Bodens ist. Die Differenzierung der Betriebsgrößen innerhalb Westdeutschlands ist auf die unterschiedlichen Erbverfahren zurückzuführen. Im Norden Westdeutschlands ist das Erbrecht stark vom Meierrecht beeinflußt, das die ungeteilte Vererbung der Höfe festlegte, während im Südwesten das Prinzip der Realteilung vorherrscht, das zur Bodenzersplitterung führte. Daneben hat sich noch eine relativ geringfügige Zahl von Großgütern feudaler Herkunft erhalten, deren Bedeutung nicht so sehr in ihrem ökonomischen Gewicht wie in der politischen Bedeutung ihrer Besitzer liegt. ${ }^{46}$ )

\section{Die vorherrschende Form, in der sich die landwirtschaftliche Produktion in der BRD vollzieht.}

Bei der theoretischen Untersuchung der verschiedenen Formen der Grundrente - absolute Grundrente und Differentialrente - geht Marx von der kapitalistischen Produktionsweise in der Landwirtschaft aus, die er folgendermaßen beschreibt: „Die Voraussetzung bei der kapitalistischen Produktionsweise (in der Landwirtschaft M. B.) ist also diese: die wirklichen Ackerbauer sind Lohnarbeiter, beschäftigt von einem Kapitalisten, dem Pächter, der die Landwirtschaft nur als ein besonderes Exploitationsfeld des Kapitals, als Anlage seines Kapitals in einer besonderen Produktionssphäre betreibt. Dieser Pächter-Kapitalist zahlt dem Grundeigentümer, dem Eigentümer des von ihm exploitierten Bodens, in bestimmten Terminen, z. B. jährlich, eine kontraktlich festgesetzte Geldsumme (ganz wie der Borger von Geldkapital bestimmten Zins) für die Erlaubnis, sein Kapital in diesem besonderen Produktionsfeld anzuwenden. Diese Geldsumme heißt Geldrente ... " ${ }^{47}$ )

Dies is: nur eine Form des Kapitalismus in der Landwirtschaft; eine andere, bei der der Großgrundbesitzer selbst die landwirtschaftlichen Lohnarbeiter ausbeutet, haben wir als die für Ostdeutschland typische bereits kennengelernt. Für beide aber ist charakteristisch, daß sich notwendigerweise - genauso wie in der Industrie - das kapitalistische Produktionsverhältnis Lohnarbeit-Kapital herstellt. Im folgenden wird untersucht, ob dieses Produktionsverhältnis das vorherrschende in der Landwirtschaft der BRD ist.

Die Arbeitskräftestatistik des Grünen Berichts 1970 weist für das Wirtschaftsjahr 1968/69 165000 ständige Lohnarbeitskräfte gegenüber 2,056 Mio vollbeschäftigten Familienarbeitskräften aus. ${ }^{48}$ ) Daraus ergibt sich ein Anteil der Lohnabhängigen von $7,4 \%$ an den Vollbeschäftigten in der Landwirtschaft. Berücksichtigt man bei der Berechnung auf der einen Seite auch die teilbeschäftigten Familienarbeitskräfte und auf der anderen die nichtständigen Lohnarbeitskräfte, erhöht sich der Anteil der Lohnabhängigen an den ins-

\footnotetext{
46a) $\mathrm{Zu}$ den politisch ambitionierten Großgrundbesitzern gehören zum Beispiel Freiherr von Kühlmann-Stumm (FDP) und Freiherr von und zu Guttenberg (CDU). Der größte Grundeigentümer in der BRD ist das Fürstenhaus Thurn und Taxis. Vgl. dazu Scheringer, Sprenger, Arbeiter und Bauern gegen Bosse und Banken", Frankfurt 1970, S. $79 \mathrm{f}$,

47) Marx, Kapital III, a. a. O., S. 631,

48) Vgl. Grüner Bericht 1970, a. a. O., S. 178,
} 
gesamt in der Landwirtschaft Beschäftigten auf 7,9\%. Diese Verhältniszahlen berücksichtigen auch die Arbeitskräfte in Nebenerwerbsbetrieben, die für den Markt produzieren. Dies ist korrekt, da die Tatsache, daß diese Betriebe nur durch die außerlandwirtschaftliche Erwerbstätigkeit eines oder mehrerer Familienmitglieder existieren können, nicht zu dem Schluß verleiten darf, daß die Nebenerwerbsbetriebe für die Landwirtschaft der BRD unbedeutend wären. Sie machten $196944 \%$ aller landwirtschaftlichen Betriebe aus und bewirtschafteten $13 \%$ der $\mathrm{LN} .{ }^{49}$ ) Ihre Bedeutung für die landwirtschaftliche Produktion ließe sich nachweisen, wenn es Statistiken gäbe, die ihren Anteil am jährlichen Produktionswert der westdeutschen Landwirtschaft auswiesen.

Folgende Tabelle soll einerseits die Bedeutung einzelner Betriebsgrößenklassen hinsichtlich der Gesamtzahl der landwirtschaftlichen Betriebe und der gesamten landwirtschaftlichen Nutzfläche (LN) verdeutlichen und andererseits einen Überblick über die Verteilung der ständigen Lohnarbeitskräfte und der vollbeschäftigten Familienarbeitskräfte auf die einzelnen Betriebsgrößenklassen geben. Betrachtet wird das Wirtschaftsjahr 1968/69.

Tab. 1

\begin{tabular}{|c|c|c|c|c|c|c|}
\hline $\begin{array}{l}\text { Betriebs- } \\
\text { größenklasse }\end{array}$ & $\begin{array}{l}0,5- \\
2 \mathrm{ha} \text { * }\end{array}$ & $\begin{array}{l}2- \\
5 \mathrm{ha}\end{array}$ & $\begin{array}{c}5- \\
10 \mathrm{ha}\end{array}$ & $\begin{array}{l}10- \\
20 \mathrm{ha}\end{array}$ & $20-$ & $\begin{array}{l}50 \text { ha } \\
\text { u. mehr }\end{array}$ \\
\hline $\begin{array}{l}\text { Zahl der } \\
\text { Betriebe in } \\
1000\end{array}$ & 132,9 & 279,2 & 252,3 & 280,6 & 149,1 & 18,0 \\
\hline $\begin{array}{l}\text { Zahl der } \\
\text { Betriebe in } \%\end{array}$ & 9,9 & 20,8 & 18,8 & 20,9 & 11,2 & 1,3 \\
\hline $\mathrm{LN}$ in $\%$ & 1,3 & 7,2 & 14,3 & 31,2 & 32,9 & 11,4 \\
\hline $\begin{array}{l}\text { ständige } \\
\text { Lohnarbeits- } \\
\text { kräfte in } \\
1000\end{array}$ & 20 & 12 & 15 & 23 & 41 & 54 \\
\hline $\begin{array}{l}\text { vollbeschäftigte } \\
\text { Familienarbeits- } \\
\text { kräfte in } \\
1000\end{array}$ & 118 & 346 & 459 & 689 & 403 & 41 \\
\hline
\end{tabular}

*) Ohne 230000 Kleinstbetriebe mit 222200 ha LN, die nicht für den Markt produzieren, d. h. mit Verkaufserlösen unter $1000 \mathrm{DM}$ jährlich.

Quellen: Grüner Bericht 1970, S. 26/27 und S. 178, Statistisches Jahrbuch über Ernährung, Landwirtschaft und Forsten 1970, S. 26. ${ }^{50}$ )

49) Vgl. Grüner Bericht 1970, a. a. O., S. 22/23,

50) Hrsg. Bundesministerium für Ernährung, Landwirtschaft und Forsten, Statistisches Jahrbuch über Ernährung, Landwirtschaft und Forsten 1970, Hamburg Berlin 1970, 
Zu der hohen Anzahl ständiger Lohnarbeitskräfte in der Betriebsgrößenklasse 0,5 - 2 ha muß bemerkt werden, daß sie auf eindeutig kapitalistisch betriebene Gartenbaubetriebe in Großstadtnähe zurückzuführen ist. Bestätigt wird diese Annahme durch die Tatsache, daß es bei dieser minimalen Betriebsgröße immerhin noch 16500 Vollerwerbsbetriebe gibt ${ }^{50}$ a), auf die die Lohnarbeitskräfte wahrscheinlich ausschließlich entfallen. Die stärkste Konzentrierung der ständigen Lohnarbeitskräfte ist mit 54000 in den 18000 Betrieben mit 50 ha und mehr vorhanden; das ergibt ein arithmetisches Mittel von 3 Lohnarbeitskräften pro Betrieb. Aber auch hier läßt sich, wie bei allen anderen Betriebsgrößenklassen, nichts über die tatsächliche Verteilung aussagen, da das statistische Material ungenügend ist.

Übrigens ist die DDR-Literatur der 50er Jahre in der Bestimmung der vorherrschenden Form der Produktion in der Landwirtschaft der BRD scharf zu kritisieren. Häufig werden in diesen Untersuchungen Betriebe über einer bestimmten Hektargröße kảpitalistisch genannt. Z. B. definieren die Autoren von „Westdeutschland unter den Gesetzen der Reproduktion des Kapitals und die Arbeiterklasse" alle Betriebe über 20 ha als kapitalistisch und schliessen dann aus der Zunahme dieser Betriebe auf die Entwicklung der kapitalistischen Produktionsweise in der westdeutschen Landwirtschaft. ${ }^{\prime \prime}$ ) Eine Untersuchung des Produktionsverhältnisses erfolgt nicht, obwohl es eins der wichtigsten Kriterien für die Bestimmung der Produktionsweise ist.

Marx stellt immer wieder heraus, daß aus Rohstoffen, Arbeitsinstrumenten und Lebensmitteln nur unter ganz bestimmten historischen Bedingungen Kapital wird. ${ }^{52}$ ) Notwendige Voraussetzung dafür ist, daß die gesellschaftliche Produktion unter spezifischen Verhältnissen vor sich geht, die sich z. B. von denen der feudalen Gesellschaft unterscheiden. Es müssen sich nämlich Lohnarbeiter als Besitzer von nichts als ihrer Arbeitskraft und Kapitalisten als Besitzer von vergegenständlicher Arbeit - Kapital - auf dem Markt gegenübertreten, es muß in diesem Sinn das kapitalistische Produktionsverhältnis, als Verhältnis von Lohnarbeit und Kapital, hergestellt sein. Wie wir sahen, ist dieses spezielle Produktionsverhältnis in dem überwiegenden Teil der landwirtschaftlichen Betriebe nicht gegeben, da der Bauer sowohl unmittelbar Produzent als auch Besitzer seiner Produktionsmittel ist. Von daher hat das Privateigentum in der Landwirtschaft einen anderen Charakter als das kapitalistische Privateigentum. Es beruht auf der eigenen Arbeit des unmittelbaren Produzenten bzw. auf der seiner Familie, während das kapitalistische Privateigentum auf der Ausbeutung fremder Arbeit beruht. ${ }^{53}$ )

50a) Vgl. Grüner Bericht 1970, a. a. O., S. 26/27,

s"7) Vgl. Altmann, Eva, u. a., Westdeutschland unter den Gesetzen der Reproduktion des Kapitals und die Arbeiterklasse, Berlin DDR 1959, S. $287 \mathrm{f}$,

c2) entfällt

53) Vgl. Marx, Kapital I, a. a. O., S.789f, 
Das spezifische Charakteristikum der kapitalistischen Produktionsweise - die Aneignung fremder Mehrarbeit - existiert also in dieser Form der Warenproduktion nicht. Daraus ergibt sich notwendigerweise ein relativ langsames Tempo der Reproduktion auf erweiterter Stufenleiter, die sich in der Landwirtschaft nicht als Akkumulation von Kapital darstellt, sondern von dieser nur äußerlich beeinflußt wird. ${ }^{54}$ ) Im Monopolkapitalismus werden bestimmte Methoden entwickelt, auf die später noch eingegangen wird, um auch in der Landwirtschaft die erweiterte Reproduktion zu forcieren.

Zusammenfassend kann man sagen, daß, wenn auch eine relativ geringe Antion in der Landwirtschaft der BRD die nichtkapitalistische Warenproduktion ist. Eindeutiger nachweisbar wäre dies, wenn der Anteil dieser nichtkapitalistischen Betriebe am jährlichen Produktionswert der Landwirtschaft errechnet werden könnte, was aber aus den bereits weiter oben angeführten Gründen nicht möglich ist.

Der Bereich der nichtkapitalistischen Warenproduktion in der Landwirtschaft ist einem immer stärker werdenden Zersetzungspozeß ausgesetzt. Das zeigt einerseits die Tatsache, daß ein großer Teil der bäuerlichen Produzenten auf ihren Betrieben nur noch existiert, weil er zugleich Lohnarbeiter ist oder elend dahinlebt. Andererseits dringt die kapitalistische Produktionsweise in die Landwirtschaft ein und fördert den Proletarisierungsprozeß der selbständigen Warenproduzenten. (Vgl. Abschnitt VII. b) .)

\section{Die ökonomische Lage der Bauern in der BRD}

Die Ursachen, die dafür verantwortlich sind, daß sich das Kapitalverhältnis in der Landwirtschaft der BRD bisher nicht allgemein durchgesetzt hat, bleiben in diesem Aufsatz unberücksichtigt, da eine Berücksichtigung die Untersuchung der Auswirkungen staatličher Eingriffe in die Landwirtschaft zur Voraussetzung hätte. Dies aber kann hier nicht geleistet werden. (Vgl. Einleitung). Im folgenden wird deshalb von der Tatsache ausgegangen, daß es einen überwiegend nichtkapitalistischen Sektor innerhalb einer kapitalistisch organisierten, ja vielfach hochmonopolisierten Gesamtwirtschaft gibt und es werden die Konsequenzen dieser Tatsache für die Lage der landwirtschaftlichen Produzenten untersucht. Die ökonomische Lage der Bauern umfaßt zwei Aspekte, nämlich erstens die Möglichkeit zur Reproduktion und erweiterten Reproduktion des landwirtschaftlichen Betriebs und zweitens die Lebensbedingungen der selbständigen Warenproduzenten. Für den Bauern als Produktionsmittelbesitzer und unmittelbaren Produzenten stellen sich diese beiden analytisch trennbaren Aspekte als untrennbare Einheit dar. Sein Einkommen ist deshalb nicht zerlegbar in einen Teil, der seinem Lohn entspricht (v) und einen anderen Teil, der zur Reproduktion seines Betriebes vorhanden ist $(m)$. Die Tilgung von Krediten, seien sie aufgenommen zur

54) Vgl. Marx, Kapital I, a.a. O., S.624, 
Reproduktion seines eigenen Lebens und dem seiner Familie oder zur Reproduktion des landwirtschaftlichen Betriebs, wirken für inn direkt sichtbar als Einkommensschmälerung. Das gilt nicht für den Abzug von seinem Mehrprodukt mittels des Preises durch die der Landwirtschaft vor- und nachgelagerten Wirtschaftsbereiche, da ihm dieser Mechanismus subjektiv nicht bewußt ist.

Diese Überlegungen haben zu folgender systematischer Darstellung in diesem Aufsatz geführt: In diesem Abschnitt über die ökonomische Lage der Bauern werden die Einkommenssituation, die Arbeitszeiten in der Landwirtschaft und die Verschuldung als Ausdruck der Einheit von Reproduktion des landwirtschaftlichen Betriebs und Reproduktion der Bauernfamilie dargestellt. In Abschnitt V. b) wird dann der Abzug vom landwirtschaftlichen Mehrprodukt aufgezeigt, nachdem die ökonomische Stellung der Landwirtschaft gegenüber den ausgegliederten Produktions- und Zirkulationsbereichen in Abschnitt V. a) verdeutlicht wurde.

\section{a) Die Einkommensituation. ${ }^{55}$ )}

In den jährlichen Berichten der Bundesregierung über die Lage der landwirtschaft (Grüne Berichte) wird ein Einkommensvergleich zwischen den in der Landwirtschaft Tätigen und den Lohnabhängigen in der gewerblichen Wirtschaft ausgewiesen. Und zwar wird ein ,gewerblicher Vergleichslohn' dem ,erzielten Lohn der Landwirtschaft' gegenübergestellt.

Der ,gewerbliche Vergleichslohn' errechnet sich aus den Bruttoarbeitsverdiensten aller rentenversicherten Arbeiter in der gewerblichen Wirtschaft (also ohne Land- und Forstwirtschaft und Bergbau) und berücksichtigt das in der Landwirtschaft gegebene Verhältnis von männlichen und weiblichen Vollarbeitskräften ${ }^{56}$ ), da bekanntlich die Frauenlöhne erheblich unter denen der Männer liegen. Er belief sich 1967 auf 9726 DM pro Arbeitskraft. ${ }^{57}$ ) Der ,erzielte Lohn der Landwirtschaft' ist gleich dem Arbeitseinkommen minus Betriebsleiterzuschlag, minus Arbeitgeberanteil zur Sozialversicherung für die mithelfenden Familienarbeitskräfte und die Lohnarbeiter, verteilt auf die Vollarbeitskräfte in der Landwirtschaft. ${ }^{58}$ ) Er war 1967 mit 6394 DM pro Vollarbeitskraft angegeben. ${ }^{59}$ ) Der erzielte Lohn der Landwirtschaft stieg zwar

55) Vgl. Rechtziegler, Emil, u. a., Westdeutsche Landwirtschaft im Strukturwandel, in: DWI-Forschungshefte, Heft 2/1966, Berlin DDR, S. $43 \mathrm{ff}$,

56) Vgl. Bericht der Bundesregierung über die Lage der Landwirtschaft und Maßnahmen der Bundesregierung (Grüner Bericht) 1968. Drucksache V/2540 des Deutschen Bundestags, S. 148,

57) Vgl. Grüner Bericht 1968, a. a. O., S. 148,

58) Vgl. Grüner Bericht 1968, a. a. O., S. 151,

\$9) Vgl. Grüner Bericht 1968, a.a. O., S. 148. Zur statistischen Kategorie „erzielter Lohn der Landwirtschaft" ist zu sagen, daß sie keine Differenzierungen innerhalb der Bauernschaft zuläßt, da sie nicht für einzelne Betriebsgrößenklassen und schon gar nicht für kapitalistische und nichtkapitalistische landwirtschaftliche Betriebe gesondert errechnet wird. 
absolut, aber der Abstand zum gewerblichen Vergleichslohn fiel von 1959/60 bis 1966/67 nie unter 21\%. Er betrug im Durchschnitt aller Betriebe 1964/65 23\%, 1965/66 33\%, 1966/67 34\%. ${ }^{60}$ ) Bei der Aufgliederung nach Betriebsgrößen ist festzustellen, daß der Abstand zum gewerblichen Vergleichslohn in den Betrieben unter 20 ha LN geringfügig höher liegt als in den Betrieben zwischen 20 und 50 ha. In den Betrieben mit 50 ha und mehr verringert sich der Abstand'im Vergleich zu dem der beiden anderen Betriebsgrößenklassen stark. Aber auch hier wird im genannten Zeitraum der gewerbliche Vergleichslohn nur in einem Jahr (1964/65) erreicht und um 6\% übertroffen. ${ }^{61}$ )

Nach Abzug eines durchschnittlichen Betrages für Steuern und Soziallasten stellt der gewerbliche Vergleichslohn die Rechengröße dar, die für die Reproduktion der Arbeitskraft des Arbeiters (Konsum unter den Bedingungen des gesllschaftlich üblichen Lebensstandards) übrig bleibt. Der erzielte Lohn der Landwirtschaft sagt dagegen aus zwei Gründen nichts darüber aus, was den in der Landwirtschaft Tätigen tatsächlich für ihre Reproduktion verbleibt.

Ersiens: Er wird pro Voll a r be its kraft errechnet; eine Vollarbeitskraft muß aber nach der Definition des Grünen Berichts nicht immer mit einer Arbeitskraft identisch sein. ,... vollarbeitsfähige männliche und weibliche Arbeitskräfte zwischen 16 und 65 Jahren, die ganzjährig im Betrieb arbeiten, (werden) als eine Vollarbeitskraft (=1 AK), Jugendliche von 14 bis 16 Jahren als eine halbe Vollarbeitskraft und Personen über 65 Jahre mit $0,3 \mathrm{AK}$ bewertet." ${ }^{62}$ ) Der für eine Vollarbeitskraft ausgewiesene Betrag kann also neben den Reproduktionskosten für die nichtarbeitenden Familienmitglieder, ebenso wie beim gewerblichen Vergleichslohn - unter Umständen die Reproduktionskosten für zwei arbeitende Personen umfassen. ${ }^{63}$ )

Zweitens: Der Ausdruck, erzielter Lohn der Landwirtschaft' erweckt die Vorstellung, daß diese gesamte Größe für den Konsum vorhanden ist. Jedoch müssen neben den Nettoinvestitionen ${ }^{64}$ ) die Zinslasten, die Pachten und Mieten (z. B. für Stallgebäude usw.) und die privaten Steuern (z. B. Vermögenssteuer, Lastenausgleichsabgaben usw.) von dieser Größe abgezogen werden, um den Betrag zu erhalten, der für den individuellen Konsum übrigbleibt. ${ }^{65}$ )

60) Vgl. Grüner Bericht 1968, a. a. O., S. 151,

61) Vgl. Grüner Bericht 1968, a. a. O., S. 151,

62) Grüner Bericht 1968, a. a. O., S. 113,

63) Vgl. Deenen, Bernd van, Bedeutung und Struktur der Landwirtschaft in Vergangenheit und Gegenwart, in: Die Wandlung der landwirtschaftlichen Arbeitsverfassung in der Industriegesellschaft, Berlin 1961, S. $57 \mathrm{f}$,

$\left.{ }^{64}\right) \mathrm{Vgl}$. Rechtziegler, Westdeutsche Landwirtschaft im Strukturwandel, a. a. O., S. 44, ${ }^{65)}$ Alle Einkommenskategorien der Grünen Berichte außer dem ,Reineinkommen“ unterstellen übrigens pacht- und schuldenfreie Betriebe, obwohl es 1966/67 rd. 696000 Betriebe im Pachtland gab und 1969 der „Fremdkapitalbesatz“ pro ha LN bei 2108 DM lag. Vgl. dazu Grüner Bericht 1970, a. a. O., S.4, 
Die Kategorie ,erzielter Lohn der Landwirtschaft', wie sie im Grünen Bericht existiert, entspricht also der Logik der bürgerlichen Ökonomie, die nicht den qualitativen Unterschied bemerkt, der zwischen dem Kauf eines Kühlschranks für einen Arbeiterhaushalt und dem Kauf eines Traktors bestent, aer are Voraussetzung der Produktion in einem landwirtschaftlichen Betrieb, nämlich Produktionsmittel ist.

Der hohe Verschuldungsgrad der Landwirtschaft ist ein Ausdruck dafür, daß der pro Vollarbeitskraft erzielte ,Lohn“ viel zu gering ist, um die unter „Zweitens" genannten Lasten zu decken und außerdem noch die Reproduktion der Bauernfamilie zu ermöglichen. (Vgl. dazu Abschnitt IV. c).

Marx bemerkt hinsichtlich des Parzelleneigentums, daß die Schranke der Produktion für den Parzellenbauern weder im Durchschnittsprọit des Kapitals noch in der notwendigen Existenz einer Grundrente bestehe, wie dies in der kapitalistischen Produktionsweise der Fall ist, sondern einzig und allein in seinem ,Arbeitslohn', d. h. den Reproduktionskosten seiner Arbeistkraft. Dieser sinke aber oft herab bis zum physischen Minimum. ${ }^{66}$ ) Außerdem stelle hier das zu zahlende Pachtgeld nur nominell Grundrente dar, da es „weit mehr als unter irgendwelchen anderen Verhältnissen einen Teil des Profits und selbst einen Abzug vom Arbeitslohn" des Bauern umfasse. ${ }^{67}$ ) Die heutigen Verhältnisse bestätigen diese Aussagen. Die elende materielle Lage von großen Teilen der Bauernschaft springt besonders deutlich in Gebieten ins Auge, wo die Möglichkeiten zur außerlandwirtschaftlichen Erwerbstätigkeit gering oder gar nicht vorhanden sind.

b) Die Arbeitszeiten in der Landwirtschaft

Ein umfassender Eindruck von der Lage der Bauern ist nur möglich, wenn ihre Einkommenssituation im Zusammenhang mit den Arbeitszeiten in der Landwirtschaft betrachtet wird.

Nach Angaben des Grünen Berichts 1970 betrug die Anzahl der Wochenarbeitsstunden in der Landwirtschaft 1968 für die männlichen Selbständigen 62,8 Stunden, für die männlichen mithelfenden Familienangehörigen 52,2 Stunden und für die männlichen Arbeiter 49,7 Stunden. Als Vergleichszahlen seien hier die Wochenarbeitsstunden der Männer im Produzierenden Gewerbe (Handwerk und Industrie) genannt: Selbständige 52,8 Stunden, mithelfende Familienangehörige 38,4 Stunden und Arbeiter 42,0 Stunden. ${ }^{68}$ ) Die Wochenarbeitszeit ist also in der Landwirtschaft durchschnittlich um 10 Stunden höher als im Produzierenden Gewerbe.

Die Arbeitszeiten der Frauen in der Landwirtschaft sind durchschnittlich nur um 9 Stunden pro Woche niedriger als die der Männer, was darauf hindeutet,

\footnotetext{
66) Vgl. Marx, Kapital III, a. a. O., S. 814,

67) Vgl. Marx, Kapital III, a. a. O., S. 818,

68) Vgl. Grüner Bericht 1970, a. a. O., S. 38,
} 
wie groß die Überarbeit gerade bei innen sein muß, da sie ,nebenbei' noch den Haushalt führen müssen. Außerdem läßt sich ein ansteigender Trend für die Arbeitszeiten der Frauen feststellen. ${ }^{69}$ )

Zu der Erhebung muß bemerkt werden, daß sie auf dem Mikrozensus beruht und sich nur auf die Woche vom 21. bis 27. April 1968 bezieht. Die Auswahl einer für die Landwirtschaft relativ ruhigen Jahreszeit und der kurze Erhebungszeitraum dürften erhebliche Verzerrungen der Wochenarbeitszeiten hervorrufen.

In der westdeutschen Literatur sind außer in detaillierten Dorfuntersuchungen, die in den 50er Jahren gemacht wurden, keine beseren Angaben über die Arbeitszeiten aufzufinden gewesen.

In der DDR-Literatur ist zwar ausgezeichnetes Material über die Arbeitszeiten vorhanden, das sich allerdings wiederum nur auf den Beginn der 50er Jahre bezieht und ausschließlich die Kleinbauern berücksichtigt. ${ }^{70}$ ) Dort werden detailliert die Folgen eines durchschnittlichen 13stündigen Arbeitstages, der jahrelang ohne Urlaub geleistet werden muß, aufgezeigt: nämlich die vorzeitige Zerstörung der Arbeitskraft durch irreparable Gesundheitsschäden, von denen auch die Kinder stak betroffen werden ${ }^{71}$ ), da die Kinderarbeit in der Landwirtschaft weit über das Maß vergleichbarer Bereiche (etwa kleine Handwerksbetriebe) hinausgeht. ${ }^{72}$ )

Zur Illustration seien noch zwei aktuelle Beispiele genannt: der ,Stern' (Heft 34/1971) gibt in einem Artikel über Bauerntöchter einen 12stündigen Arbeitstag an, und zwar bei einer Betriebsgröße von 40 ha. Die Arbeiten dieser Mädchen erstrecken sich von Stallarbeiten über Feldarbeiten bis hin zur Buchführung. Die meisten bekommen als Entlohnung ein Taschengeld und kennen keinen Urlaub. ${ }^{73}$ ) Zu demselben Ergebnis hinsichtlich der Arbeitszeit kommt Erika Runge in einem Interwiev mit zwei Bäuerinnen (Hofgröße 13 ha). ${ }^{74}$ )

Statistisches Material über die Stundenarbeitsverdienste in der Landwirtschaft ist in den Grünen Berichten nicht vorhanden, obwohl der Bundestag 1961 beschloß, ,im Grünen Bericht in Zukunft beim Lohnvergleich als Vergleichslohn neben den Jahresarbeitsverdienst auch den Stundenarbeitsverdienst heranzuziehen." ${ }^{75}$ ) Die Gründe, aus denen eine derartige Berechnung

69) Vgl. Grüner Bericht 1970, a. a. O., S. 38,

70) Vgl. Müller, Gerhard, Zur Lage der Kleinbauern in Westdeutschland, Berlin DDR 1956, S. $112 \mathrm{ff}$,

71) Vgl. Müller, Zur Lage der Kleinbauern ..., a. a. O., S. $117 \mathrm{ff}$,

72) Vgl. Planck, Ulrich, Der bäuerliche Familienbetrieb, Stuttgart 1964, S. 83 ff, Das Fehlen eines Jugendarbeitsschutzgesetzes für die Landwirtschaft weist auch auf die vorkapitalistische Produktionsweise in diesem Wirtschaftszweig hin.

73) Vgl. Grubbe, Peter, Mädchen vom Lande, in: Stern, Hamburg, Heft 34/1971, S. 74 ff,

74) Vgl. Runge, Erika, Frauen, Versuche zur Emanzipation, Frankfurt 21970, S. $141 \mathrm{ff}$,

75) Bericht über die Lage der Landwirtschaft (Grüner Bericht) 1961 und Maßnahmen der Bundesregierung (Grüner Plan) 1961. Drucksache 2400, 3. Wahlperiode, des Deutschen Bundestags, S.67, 
abgelehnt wurde, sind im Grünen Bericht 1961 aufgeführt. ${ }^{76}$ ) Ihre Fadenscheinigkeit legt die Vermutung nahe, daß man vor der Veröffentlichung derartig niedriger Stundenarbeitsverdienste zurüchschreckte. Die DDR-Autoren Rechtziegler und Jacobi errechnen für das Jahr 1964/65 einen durchschnittlichen Stundenarbeitsverdienst von 1,39 DM. ${ }^{77}$ ) Der Bruttostundenverdienst der Arbeiter insgesamt lag 1965 in der BRD bei 4,26 DM. ${ }^{78}$ )

\section{c) Die Verschuldung der Landwirschaft}

Das „Fremdkapital“ 78a) in der Landwirtschaft weist seit 1962 eine kontinuierliche Zunahme auf. Es belief sich 1969 auf rund 27,6 Mrd. DM. ${ }^{79}$ ) Das entspricht fast der Höhe der gesamten Verkaufserlöse, die 1968/69 bei rd. 29,4 Mrd. DM lagen. ${ }^{80}$ ) In der Summe von 27,6 Mrd. DM Fremdkapital ist nicht enthalten die Belastung landwirtschaftlicher Grundstücke mit Hypotheken, die von Dezember 1965 bis Dezember 1966 sprungartig von ca. 6,2 Mrd. DM auf ca. 11,1 Mrd. DM stieg und im Dezember 1969 bei ca. 10,9 Mrd. DM lag. ${ }^{80}$ a) Bei den folgenden Berechnungen mußte die Hypothekenbelastung aus statistischen Gründen unberücksichtigt bleiben.

Die Zinsleistungen der Landwirtschaft betrugen 1968/69 1,6 Mrd. DM; das sind $5,4 \%$ der Verkaufserlöse und $7,7 \%$ der Betriebsausgaben. ${ }^{87}$ )

Die absolute Höhe des Fremdkapitals bleibt hinsichtlich der Lage der Bauern aussagelos, solange keine Klarheit über die Funktion der Kredite in der Landwirtschaft besteht, d. h., ob mit ihnen in erster Linie Nettoinvestitionen finanziert oder nur Ersatzinvestitionen, d. h. Substanzverluste der Betriebe ausgeglichen werden, und ob der durch die Investitionen erzielte Einkommenszuwachs nicht nur hinreicht, den Kredit einschließlich der Zinsen zurückzuzahlen, sondern darüber hinaus einen zusätzlichen Gewinn darstellt.

Ein Anzeichen dafür, ob mit dem Fremdkapital nicht nur die erweiterte Reproduktion (Nettoinvestitionen), sondern auch ein Teil der einfachen Repro-

76) Vgl. Grüner Bericht 1961, S.66,

77) Vgl. Rechtziegler, Westdeutsche Landwirtschaft im Strukturwandel, a. a. O., S. 44,

78) Vgl. Statistisches Jahrbuch 1968, a. a. O., S. 454,

78a) Der Begriff „Fremdkapital“ ist aus der Terminologie der bürgerlichen Ökonomie und Statistik übernommen worden, obwohl er beim Leser auf den ersten Blick falsche Assoziationen hervorrufen kann, weil es späteres Nachlesen in Grünen Berichten und bürgerlicher Literatur über Landwirtschaft erleichtert. Warum unter diesem Begriff nicht Leihkapital in dem Sinn, wie Marx inn verwandte, zu verstehen ist, wird im Text ausgeführt. Dieses „Fremdkapital“ umfaßt kurz-, mittel- und langfristige Kredite und „,kapitalisierte" Renten und Altenteile. Es ist im Grunde geliehenes Geld, dessen Verwendungszweck unterschiedlich ist.

79) Vgl. Grüner Bericht 1970, a. a. O., S. 65,

80) Vgl. Grüner Bericht 1970, a. a. O., S. 47,

80a) Vgl Statistisches Jahrbuch über Ernährung, Landwirtschaft und Forsten 1970 , a. a. O., S. 140 ,

81) Vgl. Grüner Bericht 1970, a. a. O., S.65, 
duktion (Ersatzbeschaffungen) finanziert wird, ist das Verhältnis des Zuwachses von Fremdkapital zu den Nettoinvestitionen in einem bestimmten Zeitraum. Rechtziegler und Jacobi stellen für den Zeitraum von 1950 bis 1957 fest, daß die Nettoinvestitionen unter dem Niveau der Neuverschuldungen lagen, d.h., daß das Einkommen der Landwirtschaft langfristig nicht ausreichte, die Substanz der Betriebe zu erhalten. ${ }^{82}$ ) Für die folgenden Jahre konstatieren sie allerdings folgendes: "Die im Rahmen des Landwirtschaftsgesetzes ergriffenen staatsmonopolistischen Maßnahmen verbesserten zwar nicht prinzipiell die Lage der Bauern, sie trugen jedoch dazu bei, die katastrophale Situation insofern zu ändern, als nunmehr, ..., die Neuverschuldung nicht mehr das Niveau der Nettoinvestitionen erreichte." ${ }^{83}$ )

Seit dem Wirtschaftsjahr 1966/67 liegen jedoch die Nettoinvestitionen wieder erheblich unter der Zunahme des Fremdkapitals.

Tab. 2

\begin{tabular}{lccc} 
& $1966 / 67$ & $1967 / 68$ & $1968 / 69$ \\
\hline Nettoinvestitionen in Mio DM & 1306 & 1156 & 1327 \\
\hline Zunahme des Fremdkapitals in Mio DM & 2261 & 2454 & 1729 \\
\hline
\end{tabular}

Quelle: Grüner Bericht 1970, S. 62

Eine Betrachtung der ,Vergleichsrechnung' der Grünen Berichte führt zu dem Ergebnis, daß der Kredit in der Landwirtschaft vorwiegend keine typisch kapitalistische Funktion hat, d. h., daß er den Geldleiher in den allermeisten Fällen nicht in die Lage versetzt, durch die getätigten Investiionen einen Betrag zu erwirtschaften (d. h. sich Mehrarbeit von Lohnarbeitern anzueignen), der sowohl die Rückzahlung des Kredits einschließlich der Zinsen ermöglicht und darüber hinaus einen Gewinn enthält. ${ }^{84}$ )

Die Vergleichsrechnung soll Aufschluß über die Ertragslage der Landwirtschaft geben, wobei der gewerbliche Vergleichslohn als das Kriterium gilt, an dem gemessen wird, inwieweit in der Landwirtschaft Gewinne erzielt werden, also Überschüsse über die entstandenen Kosten plus den veranschlagten Reproduktionskosten der Arbeitskräfte realisiert werden.

Im Wirtschaftsjahr 1966/67 zeigten die Buchführungsergebnisse der Testbetriebe, daß auf inrer gesamten landwirtschaftlichen Nutzfläche (LN) der Ver-

82) Vgl. Rechtziegler, Westdeutsche Landwirtschaft im Strukturwandel, a. a. O., S. 48,

83) Rechtziegler, Westdeutsche Landwirtschaft im Strukturwandel, a. a. O., S. 48,

84) Vgl. Rechtziegler, Westdeutsche Landwirtschaft im Strukturwandel, a. a. O., S.51 f, 
greichsaufwand ${ }^{85}$ ) durch den Vergleichsertrag ${ }^{86}$ ) folgendermaßen gedeckt wurde ${ }^{87}$ )

auf $6,2 \%$ der LN zu 100 und mehr $\%$

$47,2 \%$ der LN zu 90 bis unter $100 \%$

$40,3 \%$ der LN zu 80 bis unter $90 \%$

$6,3 \%$ der LN zu weniger als $80 \%$.

Leider existiert keine Berechnung der Deckung des Vergleichsaufwandes durch den Vergleichsertrag, die sich anstatt auf die LN auf die einzelnen landwirtschaftlichen Betriebe bezieht. Trotzdem kann man aus dem vorhandenen Zahlenmaterial schließen, daß es in der Landwirtschaft der BRD kaum Betriebe gibt, die im Sinne der Vergleichsrechnung Gewinne erzielen.

Hinsichtlich der Buchführungsergebnisse der Testbetriebe, bei denen die Reproduktion und die erweiterte Reproduktion immer weniger aus eigenen Geldmitteln und mit steigendem Einsatz von Fremdkapital finanziert wird, wird im Grünen Bericht 1970 bemerkt: „Nach den Ergebnissen muß jedoch angenommen werden, daß ein recht großer Teil der Betriebe mit hohem Fremdkapitaleinsatz tatsächlich von der Substanz des Betriebes lebt, weil der private Verbrauch (Reproduktionskosten der Arbeitskraft, M. B.) über das erzielte Reineinkommen hinausgeht." ${ }^{88}$ ) Für solche Fälle empfielt der Grüne Bericht die Betriebsaufgabe. Wo dies nicht geschieht, beruht die Weiterexistenz auf einer Anspannung der Arbeitskraft, die das gesellschaftliche Durchschnittsmaß bei Industriearbeitern ganz erheblich übersteigt mit entsprechenden Folgen für die Gesundheit und Lebenskraft der erwachsenen und aufwachsenden Generation.

Die Gründe für die äußerst beschränkten Möglichkeiten der Landwirtschaft zur einfachen und zur erweiterten Reproduktion und daher die Gründe ihrer Verschuldung entspringen einerseits aus dem Überleben nichtkapitalistischer Warenproduktion in einer Gesellschaft mit entwickeltem kapitalistischen Produktionsverhältnis, d. h. aus der fehlenden Aneignung fremder Mehrarbeit und der ökonomischen Stellung der Landwirtschaft gegenüber den ihr vor-

85) Der ,Vergleichsaufwand' setzt sich zusammen aus dem baren und unbaren Sachaufwand, den Betriebssteuern. den Beiträgen zur Unfallversicherung, dem gewerblichen Verqleichslohn für familieneigene und familienfremde Arbeitskräfte, dem Betriebsleiterzuschlag, dem Arbe'tgeberanteil zur Sozialversicherung und dem Zinsansatz für das „Aktivkapital“. (Zum „Aktivkapital“ gehören alle im landwirtschaftlichen Produktionsprozeß eingesetzten „Kapitalgüter": Boden, Gebäude, Dauerkulturen, Maschinen, Vieh, Vorräte, Geld). Vgl. dazu Grüner Bericht 1968, a. a. O., S. 8,

86) Der ,Vergleichsertrag' enthält die baren Betriebseinnahmen und die unbaren Leistungen, die aus dem Wert des Mehrbestandes an Vieh und Vorräten, dem Wert des Eigenverbrauchs an Betriebserzeugnissen zu Einzelhandelspreisen und dem Wert des Naturallohnes an Betriebserzeugnissen zu Einzelhandelspreisen bestehen. Vgl. dazu Grüner Bericht 1968, a. a. O., S. 8,

$\left.{ }^{87}\right)$ Vgl. Grüner Bericht 1968, a. a. O., S. 143,

88) Grüner Bericht 1970, a. a. O., S. 98, 
und nachgelagerten Wirtschaftsbereichen. Andererseits sind sie im Privateigentum an Grund und Boden zu suchen, denn es hat zur Voraussetzung, daß für den Boden ein Geldbetrag ausgelegt wird, der nicht in die Produktion eingeht, da er dem Käufer nur einen Eigentumstitel vermittelt. Dies gilt sowohl für die bäuerliche als auch für die Form der kapitalistischen Landwirtschaft, bei der der Grundbesitzer zugleich landwirtschaftlicher Kapitalist ist. Bei der bäuerlichen Landwirtschaft hat dies eine Verminderung des Umfangs der Produktionsmittel zur Folge, bei der kapitalistischen Landwirtschaft eine Verminderung des Kapitals, das der Kapitalist in dieser Produktionsphäre anlegen will. ${ }^{89}$ )

Der Kauf und Verkauf von Boden für die landwirtschaftliche Produktion ist in der BRD zwar äußerst selten, aber das oben Gesagte trifft auch bei der Vererbung von Grund und Boden zu. Der Hoferbe jeder neuen Generation muß an seine Miterben anteilmäßig auch den Wert des von inm geerbten Bodens auszahlen, was ein nicht zu unterschätzender Grund für die hohe Verschuldung in der Landwirtschaft ist.

Die ökonomische Lage der Bauern in der BRD zeigt sehr deutlich, daß die Weiterexistenz einer bäuerlichen Landwirtschaft in einer kapitalistischen Gesellschaft keineswegs in der wirtschaftlichen Überlegenheit des Familienbetriebes begründet ist, wie es die herrschende Auffassung bürgerlicher Agrarwissenschaftler und sonstiger Ideologen will, sondern in der Überarbeit und Unterkonsumtion (gemessen am gesellschaftlich üblichen Lebensstandard) der unmittelbaren Produzenten. Diese Überarbeit bzw. Unterkonsumtion ist die Grenze aller politischen Versuche zur Erhaltung des ,Bauernstandes: Spätestens die Töchter und Söhne dieser Bauern werden die volle Verwandlung in Lohnarbeiter mit dem gesellschaftlich normalen Lebensstandard vorziehen, soweit sie die Möglichkeit dazu haben. Den Übergang bildet häufig die Doppelexistenz als Arbeiterbauern (Nebenerwerbs- und Zuerwerbsbetriebe).

\section{v. Die besondere ökonomische Stellung der Landwirtschaft gegenüber den ausgegliederten Produktions- und Zirkulationsbereichen und ihre Folgen.}

Aufgrund der bäuerlichen Struktur findet der Konzentrations- und Zentralisationsproze $B$ in der Landwirtschaft nur sehr begrenzt statt und steht hinsichtlich seines Ausmaßes in keinem Vergleich zu dem der Wirtschaftsbereiche, in denen die kapitalistische Produktionsweise herrscht.

$1969 \mathrm{gab}$ es in der BRD insgesamt rd. 1,3 Mio landwirtschaftliche Betribe ${ }^{90}$ ), d. h. auch eine ebenso große Anzahl von Anbietern landwirtschaftlicher Produkte und Käufern landwirtschaftlicher Produktionsmittel (Betriebsmittel).

${ }^{89)}$ Vgl. dazu Marx, Kapital III, a. a. O., S. $816 \mathrm{ff}$,

90) Vgl. Grüner Bericht 1970, a. a. O., S. 23, 
Selbst bürgerliche Ökonomen bemerken zu dieser Tatsache, daß die Konkurrenz auf den Agrarmärkten $\mathrm{zu}$ voll kommmen sei. ${ }^{{ }^{91}}$ ) In den der Landwirtschaft vor- und nachgeschalteten Wirtschaftsbereichen - der Nahrungsmittelindustrie, dem Nahrungsmittelhandel, der Landmaschinenindustrie und der chemischen Industrie - ist dagegen eine überaus starke Zentralisation festzustellen.

a) Die Monopolisierung innerhalb der ausgegliederten Produktions- und Zirkulationsbereiche.

1. Nahrungsmittelindustrie und Nahrungsmittelhandel

Als Käufer landwirtschaftlicher Produkte treten der Landwirtschaft sowohl Verarbeiter (Konservenfabriken usw.) als auch Erfassungshändler (Genossenschaften, Landhandel) und der Nahrungsmittelhandel gegenüber. Die besondere Form der Beziehung, die sich zwischen Verarbeitern und Landwirtschaft herausgebildet hat, nämlich die vertikale Integration, wird später dargestellt werden. (Vgl. Abschnitt VII. b.)).

Der Grad der Zentralisation in der Nahrungsmittelindustrie soll am Beispiel der Nährmittelindustrie, der Zuckerindustrie und der Fleischwarenindustrie aufgezeigt werden.

In der Nährmittelindustrie entfielen 1967 auf vier Betriebe 37,7\% des Umsatzes, auf weitere fünf Betriebe entfielen $17,5 \%$ oder aber anders ausgedrückt: $6 \%$ der Betriebe in diesem Industriezweig vereinigten 55,2\% des Umsatzes auf sich. ${ }^{92}$ )

In der Zuckerindustrie haben die Süddeutsche Zucker AG und die Zuckerfabrik Franken GmbH (von deren Kapital sich 25\% im Besitz der Süddeutschen Zucker AG befinden) einen Marktanteil von 34\%, weitere $12 \%$ entfallen auf ein drittes Unternehmen. ${ }^{93}$ ) Die Situation in der Zuckerindustrie anderer EWG-Staaten (in Italien kontrolliert ein Zuckerkonzern den Zuckermarkt, in den Niederlanden zwei Konzerne, von denen der größere einen Marktanteil von $60 \%$ hat; in Belgien fallen $80 \%$ der Zuckerproduktion auf ein Unternehmen ${ }^{94}$ ) ) läßt darauf schließen, daß der Konzentrations- und Zentralisationsproze $B$ in der BRD in dieser Branche noch fortschreiten wird.

In der Fleischwarenindustrie der BRD vereinigen die vier größten Unternehmen knapp ein Viertel des Umsatzes auf sich. ${ }^{95}$ ) Unter diesen vier Unternehmen befindet sich die Großeinkaufsgenossenschaft Deutscher Konsum-

\footnotetext{
91) Vgl. Giersch, H., Allgemeine Wirtschaftspolitik - Grundlagen, 1. Bd., Wiesbaden 1960, S. $227 \mathrm{f}$,

92) Vgl. Rechtziegler, Emil, Westdeutsche Landwirtschaft im Spätkapitalismus, in: DWI-Forschungshefte, Heft 4/1969, Berlin DDR, S.61,

93) Vgl. Rechtziegler, Westdeutsche Landwirtschaft im Spätkapitalismus, a. a. O., S. $62 \hat{i}$,

94) Vgl. Rechtziegler, Westdeutsche Landwirtschaft im Spätkapitalismus, a. a. O., S. 63,
} 
gesellschaften $\mathrm{mbH}$, die auch einen erheblichen Machtfaktor im Nahrungsmittelgroßhandel darstellt. Rechtziegler bemerkt, daß in der westdeutschen Nahrungsgüterwirtschaft die sarke Tendenz zu beobachten ist, daß einzelne Konzerne sowohl die Erfassung, als auch die Verarbeitung landwirtschaftlicher Produkte und den Absatz an den Einzelahndel in sich vereinigen. ${ }^{96}$ ) Die Einzelheiten der Konzentration und Zentralisation im Nahrungsmittelhandel darzustellen, ginge über den Rahmen dieser Arbeit hinaus. Deshalb sollen hier nur die groben Tendenzen aufgezeigt werden, die auf eine Monopolisierung hinweisen. Die Struktur des Lebensmitteleinzelhandels hat sich seit 1950 grundlegend gewandelt. Von 1950 bis 1967 ist der Anteil des nichtorganisierten Einzelhandels am Umsatz von $66,6 \%$ auf $3 \%$ gesunken ${ }^{97}$ ), während die Zusammenschlüsse und Großbetriebsformen ihre wirtschaftliche Position verstärken konnten. Ihr Anteil am gesamten Einzelhandelsumsatz stieg von 1950 bis 1968 von $12 \%$ auf $31 \% .{ }^{98}$ ) "Mehr als 97 Prozent des Nahrungsmitteleinzelhandelsumsatzes entfallen auf Geschäfte, die eng mit Einkaufsgenossenschaften, Einkaufsketten oder -zentralen auf der Stufe des Verteilergroßhandels zusammenarbeiten bzw. von diesen abhängig sind, wie das bei den Einkaufsketten in der Regel der Fall ist. Die auf diese Weise ,organisierten' Einzelhändler beziehen etwa 50 bis 70 Prozent ihres Bedarfs über die Einkaufszentrale, der sie angeschlossen sind." ${ }^{99}$ ) D. h., die Nachfrage nach landwirtschaftlichen Produkten geht von einer geringen Anzahl marktbeherrschender Unternehmen aus. Die Konzentration im Lebensmittelhandel erzwingt die Konzentration des Angebots landwirtschaftlicher Produkte und die Produktion großer Mengen mit einheitlicher Qualität, was unmittelbare Auswirkungen auf den Produktionsprozeß in der Landwirtschaft hat. ${ }^{100}$ )

\section{Landmaschinen- und Düngemittelindustrie}

Der Monopolisierungsgrad in der Landmaschinenindustrie geht aus Tabelle 3 hervor. Leider stammt das Material aus der Mitte der 50er Jahre, so daß darin noch Maschinen enthalten sind, deren Bedeutung für die Landwirtschaft inzwischen stark gesunken ist (z.B. Dreschmaschinen), während die Anwendung anderer Maschinen gerade erst begann (z. B. Melkmaschinen). Das letztere schließt nicht die Möglichkeit aus, daß die Produktion dieser

95) Vgl. Rechtziegler, Westdeutsche Landwirtschaft im Spätkapitalismus, a.a.O., S. $63 \mathrm{f}$,

96) Vgl. Rechtziegler, Westdeutsche Landwirtschaft im Spätkapitalismus, a. a. O., S.59, $\left.{ }^{97}\right) \mathrm{Vgl}$. Rechtziegler, Westdeutsche Landwirtschaft im Spätkapitalismus, a.a. O., S. 70 ,

98) Vgl. Thimm, Die Nahrungswirtschaft, a. a. O., S. 118,

${ }^{99}$ ) Rechtziegler, Westdeutsche Landwirtschaft im Spätkapitalismus, a. a. O., S.71,

100) Vgl. zum Problem der Monopolisierung im Lebensmittelhandel: Oppen, Möglichkeiten und Grenzen..., a. a. O., S. 29 ff, und Thimm, Die Nahrungswirtschaft, a. a. O., S. $116 \mathrm{ff}$, 
Maschinen später noch von anderen Unternehmen aufgenommen wurde. Die Angaben über die Anzahl der Unternehmungen enthalten Doppelzählungen, da ein Betrieb meistens nicht auf die Herstellung einer einzigen Landmaschinenart spezialisiert ist.

Tab. 3

Grad der Konzentration in der Produktion ausgewählter Landmaschinen (Stand etwa 1955)

\begin{tabular}{lccc}
\hline Maschinenart & $\begin{array}{c}\text { Anzahl } \\
\text { der Firmen }\end{array}$ & $\begin{array}{c}\text { Anzahl } \\
\text { der Großfirmen }\end{array}$ & $\begin{array}{c}\text { Anteil der Groß- } \\
\text { firmen an der } \\
\text { Produktion in \% }\end{array}$ \\
\hline Düngerstreuer & 35 & 3 & 80 \\
\hline Heuerntemaschinen & 43 & 4 & 69 \\
\hline Rübenerntemaschinen & 34 & 3 & 90 \\
\hline Kartoffelerntemaschinen & 36 & 3 & 65 \\
\hline Dreschmaschinen & 22 & 4 & 55 \\
\hline Heu- u. Strohpressen & 9 & 3 & 85 \\
\hline Luftbereifte Ackerwagen & 18 & 3 & 60 \\
\hline Melkmaschinen & 5 & 1 & 88 \\
\hline
\end{tabular}

Quelle: Pluquet, Hans-Peter, Die Preisbildung landwirtschaftlicher Produktionsmittel, Diss., Marburg 1960, S. 101

Für den Mähdrescher, der erst in den 60er Jahren für die Landwirtschaft der BRD zunehmende Bedeutung gewann, seien hier noch folgende Zahlen genannt: 1967 vereinigten die drei größten Mähdrescherproduzenten einen Marktanteil von rd. 86\% auf sich, wobei allein die Gebr. Claas Maschinenfabrik $\mathrm{GmbH}$ einen Marktanteil von rd. $66 \%$ besaß. ${ }^{101}$ )

In der Ackerschlepperindustrie besaßen 1967 die acht größten Unternehmen einen Marktanteil von 67,5\%, sechs weitere Konzerne, darunter Ford, Daimler-Benz, Renault und Fiat, besaßen 15,2\%. ${ }^{102}$ )

Die stärkste Monopolisierung im Bereich der landwirtschaftlichen Produktionsmittel besteht in der Düngemittelindustrie. ${ }^{103}$ ) Für die Kalidüngemittel und die

101) Vgl. Rechtziegler, Westdeutsche Landwirtschaft im Spätkapitalismus, a. a. O., S. 75 ,

102) Vgl. Rechtziegler, Westdeutsche Landwirtschaft im Spätkapitalismus, a. a. O., S. 75,

103) Die Konzentration in der Düngemittelindustrie der BRD ist am umfassendsten von Pluquet, Hans-Peter, Die Preisbildung der landwirtschaftlichen Produktionsmittel, Diss., Marburg 1960, aufgearbeitet worden. Leider ist das Material schon etwas veraltet. 
Phosphorsäuredüngemittelindustrie ist es typisch, daß sich die existierenden Betriebe kartellmäßig zusammengeschlossen haben. Die Erzeugung von Kalidüngemitteln verteilt sich auf acht Unternehmen, deren Kartellzusammenschluß die ,Verkaufsgemeinschaft Deutscher Kaliwerke $\mathrm{GmbH}^{\prime}$ ist, die den gesamten Absatz für Kalidünger durchführt. ${ }^{104}$ ) Das Thomasphosphat-Syndikat besteht aus zwölf Hüttenwerken, das Superphosphat-Syndikat bestand aus dreizehn Unternehmen. Es wurde 1963 offiziell verboten, was jedoch nicht zu einer Senkung der Preise führte. ${ }^{105}$ ) Am Stickstoffdüngemittelmarkt haben die Badische Anilin- \& Soda-Fabrik AG und die Farbwerke Höchst AG einen Anteil von $60 \%$. Auf die Ruhr-Stickstoff-AG entfallen die restlichen $40 \%$. ${ }^{106}$ ) Die Monopolisierung führt unter anderem dazu, daß ausländische Konkurrenten, die billigere Düngemittel auf dem westdeutschen Mart anbieten könnten, ausgeschlachtet werden, wie dies im Fall des Thomasphosphats geschah. ${ }^{107}$ ) Des weiteren wird die Einführung billigerer Düngemethoden verhindert. Z. B. gewinnt die Stickstoffdüngung mit flüssigem Ammoniak international zunehmende Bedeutung, da sie preiswerter ist als die herkömmliche Methode, aber die westdeutschen Konzerne nehmen diese Produktion nicht auf. „Um den Konzernen über hohe Preise ihre Profite zu sichern, wird also den westdeutschen Bauern eine durch den technischen Fortschritt mögliche Senkung der Düngemittelpreise vorenthalten. Es zeigt sich auch an diesem Beispiel, daß Neuerungen von den Monopolen erst dann eingeführt werden, wenn sie die Kapitalverwertung verbessern, nicht aber bereits, wenn gesellschaftliche Arbeit eingespart wird." ${ }^{108}$ ) Der Einfluß der Konzerne in der Düngemittelindustrie führte auch zu einer $20 \%$ igen Subventionierung der Düngemittelpreise im Jahre 1956, wodurch sie weiterhin in der Lage waren, ihre Monopolpreise zu realisieren. ${ }^{109}$ )

Die Beschleunigung des Konzentrations- und Zentralisationsprozesses in der gesamten Wirtschaft der BRD hat also, wie wir sahen, auch in allen Bereichen, von denen die Landwirtschaft abhängig ist, zur Herausbildung maktbeherrschender Monopole geführt. Die Folgen, die sich hieraus für den Bauern ergeben, werden im folgenden Abschnitt aufgezeigt.

104) Vgl. Pluquet, Die Preisbildung ..., a. a. O., S.165 ff,

105) Vgl. Rechtziegler, Westdeutsche Landwirtschaft im Spätkapitalismus, a. a. O., S. 78 ,

106) Vgl. Rechtziegler, Westdeutsche Landwirtschaft im Spätkapitalismus, a. a. O., S. 77 ,

107) Vgl. Rechtziegler, Westdeutsche Landwirtschaft im Spätkapitalismus, a. a. O., S. 78 ,

${ }^{108)}$ Rechtziegler, Westdeutsche Landwirtschaft im Spätkapitalismus, a. a. O., S.78, $\left.{ }^{109}\right)$ Vgl. Hansmeyer, K.-H., Finanzielle Staatshilfen für die Landwirtschaft, Tübingen 1963, S. $139 \mathrm{ff}$, Die Düngemittelsubventionen wurden 1963 zum letzten Mal gezahlt. Vgl. Statistisches Jahrbuch über Ernährung, Landwirtschaft und Forsten 1968, a. a. O., S. 228 , 
b) Der Abzug vom landwirtschaftlichen Mehrprodukt mittels des Monopolpreises.

Die schwache ökonomische Stellung der ländlichen Produzenten ermöglicht den monopolisierten vor- und nachgeschalteten Bereichen die Aneignung eines Teils des landwirtschaftlichen Mehrprodukts über die Monopolpreisbildung.

Die Voraussetzungen für den Monopolpreis sind ein künstliches oder natürliches Monopol ${ }^{110}$ ), eine genügende Nachfrage und damit die Zahlungsfähigkeit der Käufer. ${ }^{\prime \prime}$ ) Alle drei Voraussetzungen sind in der Beziehung zwischen Produktionsmittelindustrie und Landwirtschaft erfüllt. Die Produktion der landwirtschaftlichen Produktionsmittel ist, wie wir sahen, in wenigen monopolistischen Betrieben konzentriert; die Nachfrage wird ständig gesteigert, da für den Bauern die einzige Möglichkeit, seine Lage zu verbessern, in der Steigerung der Produktion liegt, was nur durch vermehrten Produktionsmitteleinsatz erreicht werden kann; die Zahlungsfähigkeit wird durch die Aufnahme von Krediten und durch Subventionen hergestellt. Die Bildung der Monopolpreise kann auf der Grundlage von Preiserhöhungen, aber auch bei gleichbleibendem oder fallendem Preisniveau vor sich gehen. „Bei gleichbleibendem Preisniveau entstehen Monopolpreise, wenn durch das Steigen der Arbeitsproduktivität der Marktwert fällt und das Monopol eine Verbillgung dieser Waren verhindert. Monopolpreise gibt es auch bei fallendem Preisniveau, wenn der kapitalistische Kostpreis schneller fällt als die Warenpreise fallen." ${ }^{112}$ )

Der Abzug vom landwirtschaftlichen Mehrprodukt über den Preis wird vielfach auch von bürgerlichen Ökonomen erkannt. Stellvertretend sei hier aus den programmatischen Erklärungen der SPD zur Agrarpolitik (1960) zitiert: „Die landwirtschaftliche Bevölkerung hat Anspruch darauf, da $B$ ihr die industriellen Güter - landwirtschaftliche Betriebsmittel ebenso wie allgemeine Gebrauchsgegenstände - so preisgünstig wie möglich zur Verfügung gestellt werden. Die allgemeine Wirtschaftspolitik muß insbesondere dafür sorgen, daß in jenen Bereichen der Wirtschaft, in denen hohe Rationalisierungserfolge erzielt werden und deren Märkte in der Regel von wenigen grossen Unternehmen beherrscht werden, die eintretenden Kostensenkungen durch niedrige Preise an die Verbraucher weitergegeben werden. " ${ }^{113}$ )

Die Entwicklung der Indizes der Erzeugerpreise landwirtschaftlicher Produkte (die Preise, die der Bauer für seine Waren realisiert) und der landwirtschaftlichen Betriebsmittelpreise zeigen, $d a ß$ es für die Landwirtschaft unmöglich ist, gestiegene Produktionskosten über die Preise weiterzugeben. ${ }^{114}$ )

110) Vgl. Marx, Kapital III, a. a. O., S. 868 f,

111) Vgl. Marx, Kapital III, a. a. O., S. 772,

112) Heinke, Alfred, u.a., Wer bestimmt die Agrarpreise?, Berlin DDR 1959, S. 21 ,

113) Hrsg. SPD-Parteivorstand, Der Bauer in der Welt von morgen, Arbeitsmaterial zu Agragpolitik Hannover 1960, S. 17,

${ }^{114}$ ) Vgl. Grüner Bericht 1970, a. a. O., S. 46, 
Die Erzeugerpreise ausgedrückt in Prozent der Betriebsmittelpreise geben den Verlauf der für die Landwirtschaft typischen Preis-Kosten-Schere wieder, die sich in den Jahren 1962/63 und 1963/64 fast und 1966/67 erstmals tatsächlich schloß.

$\operatorname{Tab} .4$

\begin{tabular}{lllllll}
\hline $1962 / 63$ & $1963 / 64$ & $1964 / 65$ & $1965 / 66$ & $1966 / 67$ & $1967 / 68$ & $1968 / 69$ \\
\hline 100,8 & 100,7 & 102,7 & 105,9 & 99,5 & $94,2 *$ & 100,2 *
\end{tabular}

* wegen der Änderung des Umsatzsteuersystems nur bedingt mit den Vorjahren vergleichbar.

Quelle: Grüner Bericht 1970, S.50.

$\mathrm{Da} \beta$ sich die für die Landwirtschaft negative Entwicklung fortsetzt, zeigt sich in der Tatsache, daß der Preisindex für Agrarprodukte im September 1970 gegenüber dem gleichen Vorjahrsmonat um $7,4 \%$ niedriger war, während die Betriebsmittelpreise um $5,3 \%$, anstiegen. ${ }^{115}$ )

Heinke stellt die These auf, daß in der Beziehung zwischen Nahrungsmittelindustrie und -handel einerseits und der Landwirtschaft andererseits die Kehrseite des überhöhten Monopolpreises, nämlich der niedrige Monopolpreis (Unterwertpreis) wirkt ${ }^{116}$ ), d. h., die Monopole zwingen die selbständigen Warenproduzenten, ihre Waren unter dem Wert zu verkaufen. Das könne sogar zu einem Abzug eines Teils des Wertes führen, der in der zur Reporduktion der Arbeitskraft notwendigen Arbeitszeit geschaffen wird. ${ }^{117}$ ) Die Existenz ländlicher Verelendungsgebiete (Emsland, Hunsrück, Vogelsberg, Rhön, Bayerischer Wald, Teile der Oberpfalz usw.), die deshalb welche sind, weil dort die Bauernfamilien ausschließlich von ihrer landwirtschaftlichen Tätigkeit leben müssen, könnte ein Indiz dafür sein.

Der Abzug vom bäuerlichen Mehrprodukt durch Nahrungsmittelindustrie und -handel wird deutlich, wenn man die Entwicklung des Anteils der Verkaufserlöse der Landwirtschaft an den Verbraucherausgaben für Nahrungsmittel unter Berücksichtigung der Tabelle 4 betrachtet. Diese Entwicklung gibt Auskunft über das Ausmaß der Verarbeitungs- und Handelsspannen.

115) Vgl. Bauernverband sieht schwere Benachteiligung, in: ,Der Tagesspiegel', Berlin, Ausgabe vom 11.11.'70,

116) Vgl. Heinke, Wer bestimmt die Agrarpreise?, a. a. O., S. 21 ff,

117) Vgl. Heinke, Wer bestimmt die Agrarpreise?, a. a. O., S. $19 \mathrm{f}$, 
Tab. 5

Anteil der Verkaufserlöse der Landwirtschaft an den Verbraucherausgaben für inländische Nahrungsmittel in \%.

\begin{tabular}{lcccc}
\hline & $\begin{array}{l}\text { Brotgetreide u. } \\
\text { Brotgetreide- } \\
\text { erzeugnisse }\end{array}$ & Speisekartoffeln & Gemüse & $\begin{array}{l}\text { Schlachtvieh } \\
\text { u. Fleisch u. } \\
\text { Fleischwaren }\end{array}$ \\
\hline $1960 / 61$ & 24,1 & 69,7 & 34,3 & 58,9 \\
$1961 / 62$ & 22,1 & 70,4 & 33,8 & 56,1 \\
$1962 / 63$ & 20,7 & 72,4 & 36,6 & 54,3 \\
$1963 / 64$ & 19,8 & 66,9 & 30,8 & 55,4 \\
$1964 / 65$ & 19,1 & 69,0 & 29,9 & 52,9 \\
$1965 / 66$ & 17,9 & 71,4 & 32,4 & 53,4 \\
$1966 / 67$ & 17,4 & 66,1 & 30,4 & 51,8 \\
$1967 / 68$ & 15,1 & 62,0 & 29,1 & 50,1 \\
$1968 / 69$ & 14,9 & 58,1 & 33,7 & 54,6 \\
\hline
\end{tabular}

Quelle: Grüner Bericht 1970, S. 171,

Rechtziegler bemerkt zum Problem der Ausweitung der Handelsspannen: „Das ganze Ausmaß der Spannenausweitung kann auf keinen Fall durch einen steigenden Verarbeitungsgrad der landwirtschaftlichen Erzeugnisse und Kostensteigerungen in diesem Bereich erklärt werden. Ohne Zweifel haben beide Faktoren in einem gewissen Umfang bei einigen Produkten zu grösseren Handels- und Bearbeitungsspannen geführt ... (Es zeigt sich aber), daß dieser Entwicklung andere Ursachen zugrunde liegen, denn die Ausweitung der Handels- und Bearbeitungsspannen war in jenen Jahren besonders groß, in denen die landwirtschaftlichen Erzeugerpreise sanken. Das Monopolkapital nutzte als seine Marktmacht aus, um gerade dann die Spannen stark auszuweiten, wenn die Landwirtschaft sich in einer ökonomisch besonders ungünstigen Lage befand. In den folgenden ausgeglicherenen Wirtschaftsjahren wurden die Spannen von den Monopolen dann aber nicht wieder gesenkt... Selbst bei Erzeugnissen, deren Verarbeitungsgrad, Verpackung usw. sich kaum oder gar nicht verändert hat, ist die Handelsspanne gestiegen, obwohl die Rationalisierung der Produktion und das Wachstum der Arbeitsproduktivität in diesen Zweigen nicht gering war." ${ }^{118}$ )

Auf dem Hintergrund dieser Tatsachen erscheint die Diskussion um die Forderung des Bauernverbandes nach einer 10\%igen Erhöhung der landwirtschaftlichen Erzeugerpreise im Herbst 1970, die in der bürgerlichen Presse geführt wurde, lächerlich. Denn eine Erhöhung der Erzeugerpreise um 10\%

118) Rechtziegler, Westdeutsche Landwirtschaft im Strukturwandel, a. a. O., S. 13 f, 
hätte nur eine 1-2\%ige Erhöhung der Lebensmittelpreise zur Folge ${ }^{119}$ ), vorausgesetzt, die Konzerne in Nahrungsmittelindustrie und -handel benutzen die Steigerung der Erzeugerpreise nicht als Vorwand, ihre Monopolprofite auszuweiten.

Die schwache ökonomische Position der Landwirtschaft der BRD gegenüber den Monopolen wird aus folgenden zwei Gründen noch verschärft:

Erstens werden die westdeutschen Agrarpreise durch die Konkurrenz ausländischer Agrarprodukte gedrückt. ${ }^{120}$ )

Zweitens ist die Landwirtschaft stark von der Tendenz zur relativen Überproduktion betroffen (Überproduktion im Verhältnis zur zahlungsfähigen Nachfrage - z. B. können sich kinderreiche Arbeiterfamilien und Arbeiterrentner nur in engen Grenzen Butter, Fleisch usw. kaufen). Die niedrigen landwirtschaftlichen Erzeugerpreise bedingen neben anderen Faktoren die schlechte ökonomische Situation der selbständigen Warenproduzenten. Die einzige Möglichkeit für ‘sie, diese zu verbessern, besteht aber in der Ausweitung der Produktion. Ein größer werdendes Angebot bei etwa gleichbleibender Nachfrage erleichtert wiederum den Druck auf die Preise. - Dies sind die Gründe für die relative Überproduktion in der Landwirtschaft, die an der Oberfläche sichtbar werden.

\section{Die Behinderung der Weiterentwicklung der Produktivkraft der Arbeit durch die bäuerliche Landwirtschaft.}

Mit der vom Kapital immer weiter vorangetriebenen Entwicklung der Produktivkräfte gerät das vorkapitalistische Produktionsverhältnis der Landwirtschaft in immer größeren Widerspruch zu innen. Die geringe Größe der bäuerlichen Betriebe und die Zersplitterung der Produktion erzwingen z. B. einen relativ hohen Einsatz von Produktionsmitteln pro ha $L N$, und zwar ist dieser Einsatz umso höher, je geringer die Anbaufläche des Betriebes ist. Diese Tatsache ist an der Entwicklung der Nettoinvestitionen nach Betriebsgrößenklassen in der BRD seit 1956/57 festzustellen. 1968/69 betrugen die Nettoinvestitionen in Betrieben unter 20 ha $L N 222 \mathrm{DM} / \mathrm{ha} L N$, in Betrieben mit 20-50 ha $162 \mathrm{DM} / \mathrm{ha} \mathrm{LN}$, in Betrieben mit 50 ha und mehr $90 \mathrm{DM} / \mathrm{ha} \mathrm{LN} .{ }^{121}$ ) Obwohl ein Teil des höheren Produktionsmitteleinsatzes pro ha in den kleineren Betrieben auf die intensivere Bewirtschaftung zurückzuführen ist, sieht man doch, wie unrationell diese Betriebe arbeiten müssen. Schon dieses Beispiel zeigt, daß unter den Voraussetzungen eines anderen Produktionsverhältnisses die in der Landwirtschaft verausgabte gesellschaftliche Arbeit viel geringer sein könnte, um ein gleich großes Produkt zu erbringen.

119) Vgl. Müller, Roland, Bauern pfeifen Minister Ertel aus, in: ,Frankfurter Rundschau“, Frankfurt, Ausgabe vom 11. 11. '70,

120) entfällt.

121) Vgl. Grüner Bericht 1970, a. a. O., S. 214, 
In dem Maße, in dem immer größere Teile des Mehrprodukts der Landwirtschaft von den monopolisierten ausgegliederten Wirtschaftsbereichen abgezogen werden (Vgl. Abschnitt V. b) ), beschränkt die bäuerliche Landwirtschaft die Verwertungsmöglichkeiten des Kapitals in diesen Zweigen.

Die Akkumulation in der landwirtschaftlichen Produktionsmittelindustrie ist zum Teil völlig (Landmaschinen- und Ackerschlepperindustrie, Futtermittelindstrie) und zum Teil schwächer (chemische Industrie, Baugewerbe) von der erweiterten Reproduktion der Landwirtschaft abhängig. In der Landmaschinenindustrie haben $1965 \mathrm{rd}$. 57000 Beschäftigte für die einheimische Landwirtschaft produziert, ${ }^{122}$ ) rd. $70 \%$ des Produktionswertes wurde im Inland abgesetzt. ${ }^{123}$ ) Die chemische Industrie setzte im selben Jahr $10 \%$ ihrer Produktion an die Landwirtschaft ab. ${ }^{124}$ I Im Abschnitt IV. c) haben wir jedoch bereits gesehen, wie beschränkt die Möglichkeiten der Landwirtschaft zur erweiterten Reproduktion sind.

Die Zersplitterung der Produktion agrarischer Rohstoffe steht in einem eklatanten Mißverhältnis zu dem hohen Konzentrationsgrad der weiterverarbeitenden Industrie und dem Nahrungsmittelhandel, die beide zur optimalen Verwertung ihres Kapitals auf die zunehmende Konzentration und Standardisierung des Angebots landwirtschaftlicher Produkte angewiesen sind. Eine Zahl soll dies Mißverhältnis verdeutlichen: Die Schweinfurth-Gruppe, größter Fleischwarenproduzent in der BRD, verarbeitete 1967 rd. 730000 Schweine. Das entspricht der Jahresproduktion von etwa 21000 mittleren landwirtschaftlichen Betrieben. ${ }^{125}$ ) Diese Zahlen dürften sich aufgrund des ständig fortschreitenden Konzentrations- und Zentralisationsprozesses in den ausgegliederten Wirtschaftsbereichen noch erhöht haben.

Die Interessen der Konzerne in den ausgegliederten Bereichen sind in Bezug auf die Landwirtschaft und untereinander äußerst widersprüchlich. Der stake Abzug vom Mehrprodukt der Landwirtschaft über den Monopolpreis einerseits und den niedrigen Erzeugerpreis landwirtschaftlicher Produkte andererseits steht dem Interesse an einer erweiterten Reproduktion der Landwirtschaft entgegen. Darüberhinaus hat die exportorientierte Industrie der BRD ein Interesse an der absoluten Einschränkung der westdeutschen Agragproduktion. Die uneingeschränkte Einfuhr billigerer Agrarprodukte würde ihre Exportmöglichkeiten vergrößern und außerdem ihrem Interesse nach möglichst niedrigen Reproduktionskosten der Arbeitskraft entgegenkommen, das sie aufgrund der Konkurrenzbedingungen auf den Auslandsmärkten stärker hat, als die Industrien, die für den Inlandmarkt produzieren. Die Durchsetzung dieses Interesse würde die Möglichkeit zur Erzielung von Monopol-

122) Vgl. Rechtziegler, Westdeutsche Landwirtschaft im Spätkapitalismus, a. a. O., S. 22,

123) Vgl. Thimm, Die Nahrungswirtschaft, a. a. O., S. 45,

124) Vgl. Rechtziegler, Westdeutsche Landwirtschaft im Spätkapitalismus, a. a. O., S. 22,

125) Vgl. Rechtziegler, Westdeutsche Landwirtschaft im Spätkapitalismus, a. a. O., S. 15, 
profiten für die Konzerne in den der Landwirtschaft vor- und nachgelagerten Bereichen beschneiden. ${ }^{126}$ ) Ein Ausdruck dieser Interessenwidersprüche war zum Beispiel der ,Hähnchenkrieg' zwischen den USA und der BRD, wo im Zuge des Inkrafttretens der EWG-Geflügelmarktordnung die Einfuhr von amerikanischen Geflügelfleisch fast völlig zum Erliegen kam. Das beantworteten die USA mit einer kräftigen Zollerhöhung für Exportwaren aus der EWG, worunter $\mathrm{u}$. a. auch der Absatz des VW-Werkes litt. ${ }^{127}$ )

Durch die aufgezeigten widersprüchlichen Interessen des Kapitals einerseits und durch den Existenzkampf der Bauern, der im Verhältnis zum allgemeinen Niveau der gegenwärtigen Klassenauseinandersetzungen in der BRD sehr radikale Formen hat, andererseits, wird der Staat in seiner Funktion als Garant der Rahmenbedingungen des kapitalistischen Reproduktionsprozesses zu Interventionen gezwungen. Es ginge über den Rahmen des Aufsatzes hinaus, diese staatlichen Maßnahmen im einzelnen darzustellen und zu analysieren. Hier sollen nur kurz ihre Funktionen genannt werden.

Zinsverbilligungsprogramme, Subventionen aller Art und die Förderung der Zentralisation des Bodens durch Landabgabeprämien sollen die Möglichkeit der Landwirtschaft zur erweiterten Reproduktion herstellen. ${ }^{127 a)}$ Die Agrarmarktordnungen mit Preisregelungen und Qualitätsbestimmungen, unter deren Regelungen 1963 rd. $86 \%$ der Verkaufserlöse der EWG-Bauern fielen, ${ }^{128}$ ) sind das wichtigste Instrument zur Konzentration und Standardisierung des Angebots landwirtschaftlicher Produkte und zur Stabilisierung der Agrarpreise, die von großer Wichtigkeit für die Kalkulation in Nahrungsmittelindustrie und -handel ist.

Widersprüchlich wie die Interessen, die diese Maßnahmen provozieren, sind auch deren Folgen. Ein großer Teil dieser Maßnahmen, die alle ihren Ursprung in dem Widerspruch zwischen der bäuerlichen Agrarstruktur und den kapitalistisch entwickelten Produktivkräften in der gesamten Gesellschaft haben, tragen wiederum zur längeren Erhaltung gerade dieser Struktur bei, als es der Fall wäre, wenn sich die Folgen der Konkurrenz ungehindert auswirken könnten.

126) Vgl. Hrsg. Meißner, Herbert, Bürgerliche Ökonomie im modernen Kapitalismus, Berlin DDR 1967, S. $485 \mathrm{f}$,

127) Vgl. Ernst, Heiner, Die grüne Front, Wien Frankfurt Zürich 1965, S. $146 \mathrm{ff}$,

127a) Alle Subventionen, bei denen entweder bares Geld in den landwirtschaftlichen Betrieb fließt oder sich die Produktionskosten für den Bauern verringern, stellen staatlich durchgeführte Wertverschiebungen zugunsten der Landwirtschaft dar. Ein geringer Teil des Wertabzugs durch die vor- und nachgelagerten Wirtschaftsbereiche wird der Landwirtschaftsrat also auf diesem Weg wieder zugeführt. Diese Art staatlicher Maßnahme trägt zur Erhaltung der Landwirtschaftlichen Produzenten als Bauern ' bei, anders als z. B. eine Maßnahme wie die Landabgabeprämie, die den Konzentrations- und Zentralisationsprozeß in der Landwirtschaft fördert und somit auch die Proletarisierung eines Teils der Bauern. Von daher waren Maßnahmen der ersteren Art ein beliebtes Mittel der CDUfiCSU- zur Erhaltung eines, gesunden Mittelstandes'.

128) Vgl. Ernst, Die Grüne Front, a. a. O., S.76, 


\section{Die Entwicklungstendenzen in der Landwirtschaft der BRD. ${ }^{128} \mathrm{~b}$ )}

Wie wir sahen, ist die Entfaltung der kapitalistischen Produktionsweise notwendigerweise gekennzeichnet durch die Proletarisierung der unmittelbaren Produzenten, d. h. durch die Trennung von ihren Produktionsmitteln. Bei der Zerstörung der nichtkapitalistischen Warenproduktion in der Landwirtschaft haben sich neben dem ,Bauernlegen' drei besondere Formen herausgebildet, in denen sich dieser Proletarisierungsprozeß vollzieht:

1. die Entstehung einer großen Anzahl landwirtschaftlicher Zuerwerbs- und Nebenerwerbsbetriebe,

2. die vertikale Integration, bei der der unmittelbare Produzent teilweise noch Besitzer seiner Produktionsmittel ist, seines Status objektiv aber dem eines Lohnarbeiters gleicht, und

3. die Kapitalisierung einzelner landwirtschaftlicher Produktionszweige, in die Kapital hineinfließt, und wo sich dadurch das Produktionsverhältnis Lohnarbeit-Kapital in seiner reinen Form herstellt.

Die beiden letzteren Formen unterscheiden sich wesentlich von der ersten, da in diesen Fällen das Produktionsverhältnis in der Landwirtschaft selbst umgestaltet wird.

a) Der landwirtschaftliche Zuerwerbs- und Nebenerwerbsbetrieb.

Die Zuerwerbsbetriebe werden hauptberuflich bewirtschaftet. Da aber die Reproduktion der Bauernfamilie aus der landwirtschaftlichen Tätigkeit allein nicht gewährleistet ist, muß eine außerbetriebliche Tätigkeit aufgenommen werden, d.h., ein oder mehrere Familienmitglieder müssen Lohnarbeiter werden. Die Zuerwerbsbetriebe stellen zum allergrößten Teil einen Übergang vom Vollerwerbs- zum Nebenerwerbsbetrieb dar. ${ }^{128}$ a) Beim Nebenerwerbsbetrieb wird die Reproduktion der Bauernfamilie in erster Linie durch den Verkauf der Arbeitskraft gewährleistet. Der landwirtschaftliche Betrieb wird nur im Nebenberuf bewirtschaftet. ${ }^{129}$ )

Die Anzahl der Zuerwerbs- und Nebenerwerbsbetriebe in der BRD betrug 1969863400 , das sind 64\% aller landwirtschaftlichen Betriebe über 0,5 ha LN. ${ }^{\cdot 130}$ ) Bei dem überwiegenden Teil der noch bestehenden landwirtschaftlichen Betriebe hat sich also die Proletarisierung der Bauernfamilie bereits vollzogen. Allerdings läßt diese Form des Proletarisierungsprozesses das

128a) Vgl. Grüner Bericht 1970, a. a. O., S. 26 f, Dort wird betont, daß Zuerwerbsbetriebe „sozialökonomisch verhältnismäßig labil“ sind.

128b) Eine Untersuchung von bäuerlichen Zusammenschlüssen zu Formen der horizontalen Kooperation (Erzeugergemeinschaften usw.) konnte in diesem Aufsatz nicht geleistet werden. Durch die horizontale Kooperation wird die Spezialisierung in der Landwirtschaft vorangetreben; außerdem werden die Schwierigkeiten der Landwirtschaft zur erweiterten Reproduktion gemindert. Eine Einschätzung der horizontalen Kooperation findet sich bei Scheringer, Arbeiter und Bauern ..., a. a. O., S. 85 ff, deren Richtigkeit allerdings überprüft werden müßte. 
Produktionsverhältnis in der landwirtschaftlichen Produktion selbst unberührt, da die Arbeitskraft in erster Linie an einen industriellen Kapitalisten oder an das Handwerk verkauft wird. Der Zuerwerbs- bzw. Nebenerwerbsbetrieb stellt eine Zwischenform zwischen dem Status des selbständigen Warenproduzenten und dem des Lohnarbeiters dar. Lenin nennt sie "die erste Stufe zur Proletarisierung " ${ }^{131}$ ) und verweist auf die zunehmende Belastung der Bauernfamilie durch die Verlängerung des Arbeitstages bei dieser Verbindung von landwirtschaftlicher Produktion und Lohnarbeit.

Diese Form der Proletarisierung der landwirtschaftlichen Produzenten wird durch die Industrialisierung überwiegend argrarischer Regionen (zum größten Teil identisch mit den Verelendungsgebieten) staatlich gefördert ${ }^{132}$ ), denn sie entspricht den Interessen von Kapitalien in verschiedenen Produktionssphären und beseitigt zumindest vorübergehend die Gefahr von Klassenauseinandersetzungen.

Hermann Priebe, der eifrigste Apologet des Kapitals in den Reihen der westdeutschen Agrarwissenschaftler, zeigt sehr konkret die Vorteile für die Verwertung des Kapitals auf, das die Produktion in diesen vom Staat infrastrukturell erschlossenen Gebieten aufnimmt:

Erstens eröffnen sich neue Anlagesphären und die Möglichkeit einer Erhöhung der Mehrwertmasse, da sich durch die Proletarisierung der selbständigen Warenproduzenten das für das Kapital unentbehrliche Exploitionsmaterial - die Lohnarbeiterschaft - vermehrt. ${ }^{133}$ )

Zweitens kann das Kapital in diesen argrarischen Regionen mit einem überdurchschnittlichen Exloitationsgrad rechnen. Das Verhältnis der Arbeitszeit, die für die Reproduktion der Arbeitskraft notwendig ist, zur Mehrarbeitszeit, ist für das Kapital so günstig, weil zunächst die Reproduktionskosten der Arbeitskraft (der Lohn) um $25-35 \%$ niedriger angesetzt werden können als in der Stadt, da ein zusätzliches Einkommen aus der Landwirtschaft, ein eigenes Haus usw. vorhanden sind. ${ }^{134}$ ) Außerdem sind „die Antriebskräfte zur Steigerung des Lohniveaus ... in ländlichen Gebieten im allgemeinen geringer als in reinen Industriegebieten." ${ }^{135}$ ) Denn Preissteigerungen kommen auf dem Lande nicht so zum Tragen, wenn ein eigenes Haus, Gartenland usw. vorhanden ist.

Drittens zeichnen sich die ländlichen Arbeitskräfte zusätzlich noch durch große Seßhaftigkeit ${ }^{136}$ ) und ein durch ihre landwirtschaftliche Tätigkeit be-

129) Vgl. Grüner Bericht 1970, a. a. O., S. 26/27,

130) Vgl. Grüner Bericht 1970, a. a. O., S. 27,

131) Vgl. Lenin, W. I., Die Agrarfrage und die Marxkritiker, Werke Bd.5, Berlin DDR 1959, S. 220,

132) Vgl. Hrsg. Bundeswirtschaftministerium, Intensivierung und Koordinierung der regionalen Strukturpolitik, Reihe BMWi-Texte, Bonn, (1968),

133) Vgl. Priebe, Hermann, Regionale Wirtschaftspolitik als Voraussetzung einer erfolgreichen Agrarpolitik, in: Studien, Reihe Landwirtschaft, Nr. 4fi1961, Brüssel, S. 9 f, ,

134) Vgl. Priebe, Hermann, Strukturpolitik, in: Der Arbeitgeber, N.r. 2/1971, S. 69,

135) Priebe, Regionale Wirtschaftspolitik. .., a. a. O., S. 10,

136) Vgl. Priebe, Regionale Wirtschaftspolitik. ., a. a. O., S. 10 
gründetes Selbständigen-Bewußtsein aus, das maßgeblich ihr Verhalten im Berrieb bestimmt (z. B. Bereitwilligkeit zu Überstunden, keine Organisation in Gewerkschaften usw.). ${ }^{137}$ )

Neben dem nach profitablen Anlagemöglichkeiten suchenden Kapital hat die landwirtschaftliche Produktionsmittelindustrie ein Interesse an der vermehrten Entstehung von Zuerwerbs- bzw. Nebenerwerbsbetrieben, da diese landwirtschaftlichen Betriebe mehr als vorher in der Lage sind, mit dem durch den Verkauf der Arbeitskraft erzielten Lohn veraltete Produktionsmittel zu ersetzen oder sogar ihren Maschinenbestand zu erweitern.

„Es zeugt von der Tiefe der Widersprüche, daß gerade die ,Nebenerwerbslandwirte', die Schicht der ländlichen Produzenten also, die den Übergang zum Industrieproletariat schon am weitesten vollzogen hat, zu einem ausschlaggebenden Faktor des Marktes für Landmaschinen und Schlepper geworden ist, obwohl doch gerade in diesen vorwiegend zwerghaften Betrieben eine rationelle Ausnutzung der Maschinen am wenigsten möglich ist. Rund ein Viertel aller Schlepperkäufe entfiel 1959 auf sogenannte Nebenerwerbsbetriebe. Zur gleichen Zeit befanden sich $40 \%$ des Gesamtbestandes an Schleppern in dieser ,Betriebs'kategorie. Die Monopole allgemein (wegen des stabilen und niedrig bezahlbaren Arbeitskräftereservoirs) und die Landmaschinenmonopole insbesondere betrachten die Förderung der , nebenberuflichen Landbewirtschaftung als ihr ureigenes Interesse,..." ${ }^{138}$ ) Auch Rechtziegler verweist darauf, daß das Einkommen aus der außerlandwirtschaftlichen Tätigkeit in erster Linie in den landwirtschaftlichen Betrieb investiert wird und nur zu einem geringen $\mathrm{Maß}$ der Verbesserung des Lebenstsandards dient. ${ }^{139}$ )

Die Ausweitung dieser Form des Proletarisierungsprozesses findet ihre Grenzen in der Verbesserung der Agrarstruktur. In dem Maße, in dem die Vergrößerung der Anbaufläche der bestehenbleibenden Vollerwerbsbetriebe gefördert wird (durch Landabgabeprämien usw.), wird die Anzahl der Nebenerwerbsbetriebe abnehmen müssen, bzw. neue Betriebe dieser Art werden erst gar nicht entstehen können. Demgegenüber fordert Priebe im Interesse der landwirtschaftlichen Produktionsmittelindustrie und des Kapitals, das riach profitablen Anlagemöglichkeiten sucht, „der negativen Agrarstrukturpolitik (Freisetzung eines Teils der Bauern von ihrem Land, um die ve w cibenden landwirtschaftlichen Betriebe vergrößern zu können, M. B.) eine positive Konzeption entgegenzusetzen, die nicht zur Auflösung der Landwirtschait, sondern zur Ergänzung durch einen weiteren Erwerb führt . . . ${ }^{140}$ )

\footnotetext{
137) Vgl. Priebe, Strukturpolitik, a. a. O., S. 70

138) Hrsg. Meißner, Bürgerliche Ökonomie. ..., a. a. O., S. 480,

139) Vgl. Rechtziegler, Westdeutsche Landwirtschaft im Strukturwandel, a. a. O., S. 50,

140) Priebe, Strukturpolitik, a. a. O., S. 69,
} 
b) Die Durchsetzung des kapitalistischen Produktionsverhältnisses in der Landwirtschaft selbst.

\section{Die vertikale Integration oder Verbundwirtschaft.}

Die vertikale Integration oder Verbundwirtschaft hat sich in der BRD vorwiegen in den Beziehungen zwischen Landwirtschaft einerseits und Nahrungsmittelindustrie und -handel andererseits herausgebildet. Sie umfaßt in erster Linie die tierische Veredelungsproduktion (Geflügel-, Schweinemast, Eierproduktion) und die Sonderkulturen (Obst, Gemüse), also landwirtschaftliche Produkte, die einem hohen Weiterverarbeitungsgrad unterliegen oder eine starke Konzentration des Angebots erfordern.

Im folgenden bleibt die vertikale Integration auf gesetzlicher Grundlage bei Milch und Zuckerrüben außer Betracht. „Solche Formen der Liefer- und Abnahmebeziehungen können nicht unbedingt als Vertragslandwirtschaft bezeichnet werden, da die für ein vertragspartnerschaftliches Verhältnis allgemein üblichen Möglichkeiten der Kündigung oder des Partnerwechsels sowie des Aushandelns individueller Sonderbedingungen weitgehen entfallen." ${ }^{141}$ ) Oppen stellt fest, daß die Verbundwirtschaft in der Landwirtschaft formell als Kooperation bezeichnet werden kann, da sich zwei in juristischem Sinn selbständige Betriebe (landwirtschaftlicher Betrieb - industrieller Verarbeitungsbetrieb oder Handelunternehmen) zur Zusammenarbeit bereiterklären. Da diese Zusammenarbeit aber in der Form stattfindet, „daß alle unternehmerischen Entscheidungen vertraglich auf Zeit an einen der Partner delegiert werden" ${ }^{142}$ ), nämlich an den Verarbeitungsbetrieb, kommt sie einer Integration gleich, deren wichtigstes Kriterium die Einheitlichkeit der Unternehmensführung ist. Zum besseren Verständnis der vertikalen Integration sei hier ein Beispiel aus der Masthähnchenproduktion zitiert: „Geht nun ein landwirtschaftlicher Betrieb für einen seiner Betriebszweige feste Verträge über die Herstellung eines Produkts, beispielsweise Broiler (Masthähnchen, M. B.), ein, so können in diesen Verträgen möglicherweise sämtliche Entscheidungen über diesen Betriebszweig an das beteiligte Unternehmen delegiert worden sein, zum Beispiel mit Festlegung von Aufstallungstermin, Fütterungsvorschriften und Haltungsbedingungen, Ablieferungstermin, Festpreisen für Küken und Masthähnchen. Sogar die Produktionsmittel können zumindest zum Teil Eigentum des Vertragspartners sein.“" ${ }^{143}$ )

In den Verträgen werden sowohl Bestimmungen, die den unmittelbaren Produktionsprozeß betreffen, als auch die zu liefernde Menge, die Qualität und der Preis des Produkts festgelegt. ${ }^{144}$ ) Der Bauer arbeitet nur noch teilweise

$\left.{ }^{141}\right)$ Oppen, Möglichkeiten und Grenzen. .., a. a. O., S. 139,

142) Oppen, Möglichkeiten und Grenzen. .., a. a. O., S. 10

143) Oppen, Möglichkeiten und Grenzen. .., a. a. O., S.11,

144) Vgl. Oppen, Möglichkeiten und Grenzen..., a.a.O., S. 180 ff, Oppen gibt an dieser Stelle Vordrucke für Verträge in den verschiedenen Produktionszweigen wieder. Sie vermitteln einen guten Eindruck über das Ausmaß der Abhänggkeit, in die der Bauer gegenüber dem Integrator gerät. 
mit seinen eigenen Produktionsmitteln. Deutlicher wird dies an einem Beispiel aus Schweden, das sich auf die Bodenproduktion bezieht: "Im mechanisierten Feldgemüsebau wird die gesamte Ernte (einschließlich des Transports zur zentral gelegenen Dreschstation bei Erbsen) von den Verarbeitungsunternehmen durchgeführt. Der Verarbeiter liefert das Saatgut und verpflichtet sich, die besäte Fläche zu vermessen und Bodenuntersuchungen als Voraussetzung des Anbaus durchzuführen. Während der gesamten Wachstumszeit steht der Gemüsebestand unter ständiger Kontrolle der Konservenfabrik. Chemische Unkrautbekämpfung und auf Wunsch des Erzeugers auch die Schädlingsbekämpfung werden zum Selbstkostenpreis von der Fabrik durchgeführt." ${ }^{145}$ )

Der Bauer führt nur noch die Vorbereitung des Ackers und die Aussaat durch und stellt die für die Produktion wichtigste Vorausetzung zur Verfügung den Boden. Den Rest eriedigen die Lohnarbeiter des industriellen Verarbeitungsbetriebes. Dieses Beispiel zeigt sehr klar, daß der Integrator kein Kapital in Form von Grundrente verausgaben muß, denn der Boden wird für die Produktion weder von inm gekauft noch gepachtet, sondern er bleibt das Eigentum des Bauern.

Wie wir sahen, reicht der Marktpreis für Agrarprodukte nur zu einer sehr dürftigen Reproduktion der Bauernfamilie hin. Da sich aber der vertraglich festgelegte Preis für die in der Verbundwirtschaft produzierten agrarischen Rohstoffe nach dem jeweiligen Marktpreis richtet, sind durch das hiermit erzielte Einkommen auch nur die Reproduktionskosten der Arbeitskraft abgedeckt, d. h., der Bauer wird auf seinem eigenen Betrieb de facto zum Lohnarbeiter. Er hört auf, selbständiger Warenproduzent zu sein und wird zum landwirtschaftlichen Kontraktarbeiter der monopolisierten nachgelagerten Wirtschaftsbereiche. Nach Schilling unterscheidet er sich vom tatsächlichen Landarbeiter nur noch in zwei Punkten:

„1. Während im kapitalistischen Lohnarbeitsbetrieb der Unternehmer die Verluste bei Seuchen, Mißernten, Marktschwankungen usw. selbst tragen muß und der Lohnarbeiter relativ wenig betroffen ist, wird bei der, vertikalen Integration' dieses Risiko zu einem großen Teil auf den unmittelbaren Produzenten, den ,Vertragsbauern', abgewälzt.

2. Während für den Landarbeiter seine klassenmäßige Stellung, ... eindeutig ist, betrachtet sich der ,Vertragsbauer' immer noch als ,Selbständiger'. Das... veranlaßt inn auch zu stärksten Anstrengungen, um sein scheinbares Eigentum zu erhalten ..." ${ }^{746}$ )

In den Fällen, in denen der Bauer noch mit seinen eigenen Produktionsmitteln produziert, tritt die Proletarisierung durch die Verbundwirtschaft in einer verschleierten Form auf. Es entsteht ein der Heimarbeit vergleichbares Ver-

145) Oppen, Möglichkeiten und Grenzen..., a. a. O., S. 114,

146) Schilling, Horst, Probleme der westdeutschen Landwirtschaft in der zweiten Etappe der EWG, Berlin DDR 1964, S. 27, zit. nach: Imperalismus heute, a. a. O., S.313, 
Verhältnis, bei dem der unmittelbare Produzent auch teilweise mit seinen eigenen Produktionsmitteln arbeitet. Das Entgelt bemißt sich aber nur nach den Reproduktionskosten der Arbeitskraft.

Um die Bedeuung der Vertragswirtschaft der BRD abschätzen zu können, seien hier für einige landwirtschaftliche Produkte die Anteile der Verkaufserlöse aus der Vertragslandwirtschaft an den gesamten Verkaufserlösen dieser Produkte genannt. Der vertraglich gebundene Anteil der Verkaufserlöse betrug 1964/65 für

$\begin{array}{lr}\text { Getreide } & 2 \% \\ \text { Speisekartoffeln } & 1 \% \\ \text { Fabrikkartoffeln } & 50 \% \\ \text { Gemüse } & 60 \% \\ \text { Obst } & 20 \% \\ \text { Hopfen } & 80 \% \\ \text { Schweine } & \text { rd. } 1 \% \\ \text { Eier } & \text { rd. } 3 \% \\ \text { Mastgeflügel } & 72 \%{ }^{147} \text { ) }\end{array}$

Der vertraglich gebundene Anteil der Verkaufserlöse ist für die einzelnen Produkte je nach Verarbeitungsgrad sehr unterschiedlich. Z. B. werden Speisekartoffeln höchstens noch abgepackt, bevor sie an den Konsumenten gelangen, während aus Fabrikkartoffeln in einem besonderen Produktionsprozeß Stärke, Spiritus usw. hergestellt werden, die zum Teil anderen Industriezweigen wiederum als Rohstoffe dienen. Die stärkste Zunahme ist in der Geflügelproduktion zu beobachten, wo der vertraglich gebundene Anteil der Verkaufserlöse von $1961 / 62$ bis $1964 / 65$ von 43 auf $72 \%$ stieg. ${ }^{148}$ ) Die Tatsache, daß die Verbundwirtschaft staatlich gefördert wird (1970 mit 40 Mio. DM, 1971 und 1972 mit je 50 Mio. DM ${ }^{149}$ )), weist darauf hin, daß ihre Bedeutung für die Landwirtschaft zugenommen hat und noch zunehmen wird.

Zusammenfassend kann man sagen, daß sich bei der vertikalen Integration ohne formelle Veränderung des Eigentums an Boden und der Agrarstruktur die kapitalistische Produktionsweise in der Landwirtschaft herstellt. Damit finden auch die entstandenen Widersprüche zwischen der bäueriichen Warenproduktion und dem Entwicklungsstand der Produktivkraft der Arbeit (vgl.

\footnotetext{
147) Vgl. Oppen, Möglichkeiten und Grenzen. ., a. a. O., S. 96

${ }^{148)}$ Vgl. Oppen, Möglichkeiten und Grenzen. ., a. a. O., S. 96,

149) Vgl. Grüner Bericht 1970, a. a. O., S. 160,
} 
Abschnitt VI.) ihre vorläufige Lösung: das Angebot agrarischer Rohstoffe wird konzentriert und standardisiert, die beschränkten Möglichkeiten der Landwirtschaft zur erweiterten Reproduktion werden überwunden, indem der Integrator einen Teil der Produktionsmittel stellt.

\section{Die Kapitalisierung landwirtschaftlicher Produktionszweige.}

Unter der ,Kapitalisierung landwirtschaftlicher Produktionszweige verstehe ich die Anlage von Kapital in der landwirtschaftlichen Produktion. Wir haben bereits gesehen, daß industrielles Kapital in die der Landwirtschaft ausgegliederten Bereiche floß, als die Entwicklung der Produktivkräfte zur Arbeitsteilung z. B. zwischen der Produktion landwirtschaftlicher Produkte einerseits und ihrer Verarbeitung andererseits zwang. Jetzt können wir einen ähnlichen Prozeß beobachten, bei dem einzelnen Produktionszweige der Landwirtschaft (z. B. die Hähnchenmast oder die Eierproduktion) aus dem landwirtschaftlichen Betrieb ausgegliedert und in großem Maßstab von einem Kapitalisten betrieben werden. Diese kapitalistischen Unternehmen gelten nicht als landwirtschaftliche, sondern als gewerbliche Betriebe ${ }^{149}{ }_{a}$ ) und werden daher auch nicht in den Statistiken der Grünen Berichte berücksichtigt.

Die Kapitalisierung landwirtschaftlicher Produktionszweige ist in dem Maße möglich, in dem die Entwicklung der Produktivkräfte erlaubt, landwirtschaftliche Produkte industriemäßig herzustellen, d. h. die technischen und wissenschaftlichen Voraussetzungen müssen gegeben sein, die es ermöglichen, die Produktion einer starken Arbeitsteilung zu unterwerfen, so daß eine große Menge in kurzer Zeit produziert werden kann. Deshalb ist die Kapitalisierung der landwirtschaftlichen Produktion in der BRD ausschließlich in der tierischen Veredelungsproduktion zu beobachten, nämlich bei der Schweinemast ${ }^{150}$ ) und der Schweinezucht ${ }^{151}$ ), bei der Eierproduktion ${ }^{152}$ ) und der Ge. flüaelmast ${ }^{153}$ ).

Gegen die kapitalistische Bodenproduktion in dieser Form scheint zu sprechen, daß hier die Produkte nicht in dem Maße industriemäßig herzustellen sind wie bei der Veredelungsproduktion, die Abhängigkeit von nicht beeinflußbaren, natürlichen Bedingungen $z u$ groß ist und außerdem Kapital für

149a) Die Bestimmung von landwirtschaftlichen und gewerblichen Betrieben erfolgt nach dem Verhältnis von landwirts.chaftlicher Nutzfläche zu Nutzvieh. Für ieden Hektar Ackerland wird nur eine bestimmte Anzahl von Tieren als bäuerliches Nutzvieh anerkannt. Wird diese Anzahl überschritten, ailt der Betrieb als aewerblicher und unterlieat der Umsatz- und Gewerbesteuer. Für den bäıerlichen Produzenten, der sich z. B. auf die Eierproduktion spezialisiert hat und 5000 Hühner hält, ergibt sich unter Umständen die makabre Situation, daß er Land dazunachten muß, um der hohen Steuerbelastung zu entgehen. Val. dazu Rosema, Bernd, Betrogen und ohne Bewußtsein, in: Pardon, Frankfurt, Heft 5/1971, S. 29,

150) Vagl. Schmidt, Josef, Manaqer für Leaehennen und Mastschweine, in: Süddeutsche Zeitung, München, Ausgabe vom 31. 1. 1970,

151) Vgl. Bauern, wollt ihr ewig leben?, in: Die Zeit, Hamburg, Ausgabe vom 26 6. 1970 ,

152) Vol. Bauern, wollt ihr ewig leben?, a. a. O.,

153) Vgl. Rechtziegler, , Westdeutsche Landwirtschaft im Spätkapitalismus, a. a. O., S. 16f, 
den Kauf von Boden ausgelegt werden muß, bzw. eine Rente bei Pacht. Ob wohl statistisch nicht nachweisbar, scheint die, zeitgemäße' Form, in der der Kapiłalismus in die Bodenproduktion eindringt, die vertikale Integration zu sein, denn der Bauer trägt dabei das Risiko (z. B. bei Mißernten) und der Kapitalist spart dabei Kapital bzw. Rente für den Boden.

Statistisches Material über die kapitalistische Veredelungsproduktion ist in der von mir untersuchten westdeutschen Literatur nicht vorhanden. Rechtziegler gibt für die Masthühnererzeugung und die Eierproduktion folgende Zahlen an: 1966 entfielen 5,8\% der Masthühnererzeugung und 3,9\% der Eierproduktion in der BRD auf nichtlandwirtschaftliche Unternehmen. ${ }^{154}$ ) Die Kapitalisierung landwirtschaftlicher Produktionszweige scheint in der BRD also erst am Anfang zu stehen. Da sie in anderen kapitalistischen Ländern schon viel weiter fortgeschritten ist, liegt der Schluß nahe, daß sie sich auch in der BRD weiter ausbreiten wird. In den USA wurden z. B. $196740 \%$ der Masthähnchen in industriellen Betrieben produziert. ${ }^{155}$ ) Auch in den EWGLändern Italien und Frankreich entwickelt vor allen Dingen amerikanisches Kapital große Aktivitäten, um die Geflügelmast zu industrialisieren. ${ }^{156}$ )

Zwei Beispiele mögen einen Eindruck von dem Umfang der Produktion in diesen Betrieben geben: Ein Schweinemastbetrieb in der Nähe von Hamburg, der vom Unilever-Konzern betrieben wird, hat eine Jahresproduktion von 20000 Schweinen ${ }^{157}$ ); die von dem „nur die“-Strumpfkonzern betriebenen Eierfarmen haben einen Jahresausstoß von 112 Mio. Eiern ${ }^{158}$ ).

Der Widerspruch zwischen der zersplitterten landwirtschaftlichen Produktion und der Entwicklung der Produktivkräfte wird durch die kapitalistische Produktion von Agrarerzeugnissen gelöst. Den selbständigen Warenproduzenten in der Landwirtschaft mit seinen beschränkten Produktionsbedingungen muß sie ruinieren, da mit der industriellen Produktion eine Verbilligung des Produkts einhergeht. So fiel z. B. der Erzeugerpreis für Eier, der 1966 zwischen 17,1 und 18,9 Pfennigen pro Ei lag, kontinuierlich bis 1970 auf 11,9 Pfennige, wovon der Verbraucher übrigens nichts merkte. ${ }^{159}$ ) Da dem Bauern das Kapital für eine industrielle Veredelungsproduktion fehlt, wird er nach und nach aus diesen Produktionszweigen verdrängt werden und auf die Bodenproduktion beschränkt.

154) Vgl. Rechtziegler, Westdeutsche Landwirtschaft im Spätkapitalismus, a. a. O., S.16, 15\%) Vgl. Rechtziegler Westdeutsche Landwirtschaft im Spätkapitalismus, a. a. O., S. 17, 156) Vgl. Ernst, Die grüne Front, a. a. O., S. 67,

157) Vgl. Schmidt, Manager für Legehennen und Mastschweine, a. a. O., Dieser Schweinemasibetrieb des Unilever-Konzerns ist es übrigens, der im Moment die bäuerliche Seuchentasse plündert, da unter seinen 20000 Schweinen die Schweinepest ausgebrochen isi. Die Seuchenkasse ist eine Selbsthilfeeinrichtung der Bauern und besteht aus Beiträgen der Kuhhalter. Da aber auch Schweinehalter bei Seuchen Anspruch auf Entschädgung aus dieser Kasse haben, kassiert Unilever für jedes tote Schwein 80\% des Marktpreises.

i58) Vgl. Bauern, wollt ihr ewig leben? a. a. O.,

159) Vgl. Rosema, Bernd, Betrogen und ohne Bewußtsein, a. a. O., S. 29, 
Die in diesem Abschnitt aufgezeigten drei Formen - der landwirtschaftliche Nebenerwerbs- und Zuerwerbsbetrieb, die vertikale Integration und dieKapitalisierung landwirtschaftlicher Produktionszweige - , in denen sich das Kapital die bäuerlichen Produzenten unmittelbar und mittelbar unterwirft, werden sich in Zukunft sicherlich verändern. Die Auswirkung für den Bauern wird aber stets die gleiche sein, nämlich seine Verwandlung von einem selbständigen Warenproduzenten in einen Lohnarbeiter - sei es in einen Industriearbeiter oder in einen Landarbeiter -, denn der Kapitalismus läßt langfristig keine Inseln mit vorkapitalistischer Produktionsweise bestehen.

„Die bisherigen kleinen Mittelstände, die kleinen Industriellen, Kaufleute und Rentiers, die Handwerker und Bauern, alle diese Klassen fallen ins Proletariat hinab, teils dadurch, daß ihr kleines Kapital für den Betrieb der großen Industrie nicht ausreicht, und der Konkurrenz mit den größeren Kapitalisten erliegt, teils dadurch, daß ihre Geschicklichkeit (ihre spezielle Qualifikation, M. B.) von neuen Produktionsweisen entwertet wird." ${ }^{160}$ )

An die Stelle der Widersprüche zwischen dem Bauern als selbständigem Warenproduzenten einerseits und dem Kapital andererseits, die ihren Ausdruck in dem langjährigen Kampf der ländlichen Produzenten um ihre Existenz finden, tritt bei der Proletarisierung des Bauern der Widerspruch zwischen Lohnarbeit und Kapital. Als ein Exponent dieses Widerspruchs - nämlich als Lohnarbeiter - wird jedoch der Kampf um die bessere Reproduktion seiner Arbeitskraft erfolgreicher sein, da er ihn zusammen mit der Arbeiterklasse führt.

\section{Der Arbeiterbauer im Industriebetrieb.}

Die Probleme, die sich aus der Verwandlung des Bauern in einen Lohnarbeiter ergeben, sind bisher kaum untersucht worden. Auch von seiten der Gewerkschaft liegt bisher darüber nichts vor, was erstaunlich ist, wenn man bedenkt, daß allein 1970 mehr als 151000 landwirtschaftliche Arbeitskräfte, darunter 98325 ehemalige selbständige Bauern, in die Industrie abwinderten. ${ }^{161}$ ) Im übrigen ist der Proletarisierungsprozeß der Bauern noch lange nicht abgeschlossen, sondern wird sich im Zuge der Maßnahmen der EWGAgrarpolitik erheblich verstärken. Hier soll kurz angedeutet werden, was die vermehrte Einbeziehung der Bauern in die industrielle Produktion für den traditionell industriellen Teil der Arbeiterschaft eines Betriebes bedeutet.

Der Arbeiterbauer ist in erster Linie Hilfsarbeiter. Eine Untersuchung in Bayern ergab, daß proletarisierte Bauern zu 95\% Hilfsarbeițer. sind. ${ }^{162}$ ) Dies

160) Marx, Karl; Engels, Friedrich, Manifest der Kommunistischen Partei, Berlin DDR 29 1967, S. $51 \mathrm{f}$,

161) Vgl. Grubbe, Peter, Scheiß auf die Scholle!, in: Stern, Hamburg, Heft 45/1971, S. 134 ,

162) Vgl. Süddeutsche Zeitung, München, Ausgabe vom 22: 1. 1969, 
Ergebnis ist sicherlich auch für andere Bundesländer repräsentativ. Das Verhalten des Arbeiterbauern im Betrieb ist stark durch seinen früheren Status geprägt, nämlich selbständiger Warenproduzent u $\mathrm{n} d$ Landwirt gewesen zu sein (vgl. Abschnitt VII. a)). Die Erfahrungen des konkreten Arbeitsprozesses in der Landwirtschaft, wo es in Spitzenzeiten (Aussaat, Ernte) objektiv notwendig ist, länger als gewöhnlich unter Anspannung aller Kräfte zu arbeiten, werden inn zugänglicher für die Anforderungen des kapitalistischen Verwertungsprozesses z. B. nach Überstunden machen, als dies bei industriellen Lohnarbeitern der Fall ist. Sein früheres Dasein als selbständiger Warenproduzent wird inm die Einsicht in notwendiges solidarisches Handeln der Arbeiter erschweren ${ }^{163}$ ), wenn nicht gar unmöglich machen, zumal die Lohnarbeit für den Arbeiterbauern viele Vorteile gegenüber seiner früheren sozialen Lage mit sich bringt. Von innen selbst werden als Vorteile genannt die geregelte Arbeitszeit, das regelmäßige und höhere Einkommen, der Urlaub und die höhere Rente. ${ }^{164}$ ) Es bedarf sicherlich eines langen Lernprozesses, bis die Arbeiterbauern erkennen, daß dies keine verbrieften Vorteile sind, sondern vom Kapital ständig angreifbar sind und auch angegriffen werden. Die stärkste Konzentrierung von Arbeiterbauern findet sich erstens in Betrieben, die in vorwiegend agrarischen Regionen angesiedelt werden, und zweitens in Industriegebieten mit bäuerlichem Hinterland (z. B. Hamburg und Bremen für den norddeutschen Raum). Im letzteren Fall wird der Arbeiterbauer zum Pendler mit u. U. extrem langen Fahrzeiten vom und zum Arbeitsplatz. ${ }^{165}$ ) Sein besonderes Verhalten im Betrieb wird durch seine Situation als Pendler noch verstärkt, denn die Pendler stellen generell eine spezifische Fraktion innerhalb der Betriebsbelegschaft dar. Das Desinteresse an Vorgängen im Betrieb ist bei ihnen aufgrund ihrer permanenten Übermüdung besonders groß und der Kontakt zu Kollegen außerhalb der Arbeitszeit ist völlig unmöglich, zumal wenn die An- und Abfahrt in werkseigenen Bussen erfolgt. Darüberhinaus verlieren sie durch ihre lange tägliche Abwesenheit jegliche Beziehung innerhalb ihres Wohngebietes. Die Ansatzmöglichkeiten zur Agitation sind also bei diesem Teil der Arbeiterklasse überaus gering.

Die proletarisierten Bauern stellen einen Teil der Arbeiterklasse dar, der in einzelnen Punkten mit dem der ausländischen Arbeiter und dem der werk-

163) Ein Indikator dafür ist der niedrige gewerkschaftliche Organisationsgrad der Arbeiterbauern, die sich eher im Deutschen Bauernverband als im Deutschen Gewerkschaftsbund organisieren. Poppinga gibt dazu folgende Zahlen an: Von allen Arbeiterbauern in der BRD sind 30\% Mitglieder des Deutschen Bauernverbandes, während sich nur 21\% in einer Einzelgewerkschaft des Deutschen Gewerkschaftsbundes organisiert haben. Vgl. Poppinga, Onna-Hans, Zur Agrarírage in der Bundesrepublik, in: Lambert, Bernard, Bauern im Klassenkampf, Berlin 1971, S. 137,

164) Vgl. Grubbe, Scheiß auf die Scholle!, a. a. O., und Runge, Frauen..., a. a. O., S. $143 \mathrm{ff}$,

165) Die Situation der Pendler wurde in einer Sendung des Norddeutschen Rundfunks (3. Programm) am 3. 12. 71 sehr aufschlußreich dargestellt. Die Autoren dieser Sendung waren Werner Borsbach und Sieghard Hennig. Das Manuskript ist beim Norddeutschen Rundfunk erhältlich. 
tätigen Frauen vergleichbar ist. Treten die Arbeiterbauern in stärkerem Umfang in einem Betrieb auf, wird es der Kapitalist nicht unversucht lassen, sie gegen die industriellen Lohnarbeiter auszuspielen.

\section{Nachwort zur historisch-politischen Bewegung der Bauern in Deutschland}

Die folgenden Bemerkungen skizzieren thesenartig einige politische Probleme der Bauernfrage und sind als Ergänzung des vorstehenden Beitrags gedacht. Sie sind beschreibend und gehen auf die Ursachen der dargestellten Vorgänge kaum ein; sie sprechen von den Bauern als Gesamtheit, ohne weiter zwischen ihren verschiedenen Abteilungen zu differenzieren; sie beschränken sich schließlich im letzten Teil auf die Entwicklung der Bauernklasse in Westdeutschland, gehen auf die völlig unterschiedliche Entwicklung in der DDR nicht ein. Der alleinige Zweck dieser Bemerkungen ist die Aufforderung, die politischen Probleme der Bauernfrage in die Diskussion mit einzubeziehen.

1. Die Entwicklung der Bauernklasse in Deutschland war an die ökonomischpolitische Emanzipationsbewegung der deutschen Bourdeosie gebunden. Sie ist durch deren spezifische Verlaufsform bestimmt.

2. Die Bauernaufstände und-kriege (Ende des 15., Anfang des 16. Jahrhunderts) in der Phase des niedergehenden Feudalismus stellten die erste und letzte selbständige politische Artikulation der deutschen Bauern in der Neuzeit dar. Sie war in sich widersprüchlich und erhielt sowohl sozialrevolutionäre wie rüständige und sozialromantische Momente. Die aufkeimende deutsche Bourgeoisie verbündete sich mit den Territorialfürsten gegen die Bauern.

3. Die deutsche Bourgeoisie verblieb ökonomisch und politisch bis tief ins 19. Jahrhundert im Schatten der feudalabsolutistischen Staatsmacht. Während in der französischen Revolution das Bündnis von Bourgeoisie und Bauern den entscheidenden Hebel zum endgültigen Sturz des Feudalismus darstellte, war der Emanzipationsversuch der deutschen Bourgeoisie 1848 ebenso zaghaft wie ohne nennenswerten Widerhall unter den Bauern geblieben.

Die Bauern schüttelten die Fesseln der feudalistischen Produktionsweise nicht aktiv ab, sie wurden innen vom spätabsolutischen Staat (Preußen) oder von der städtischen Bourgeoisie aus ökonomischen und politischen Motiven quasi abgenommen.

4. Die Klassenkämpfe des 19. Jahrhunderts sind für "die zwischen dem Proletariat und der Bourgeoisie stehende Masse der Nation, Bauern und Kleinbürger" ") der Prozeß ihres ständigen Schwankens wie ihrer unauf-

1) Karl Marx, Die Klassenkämpfe in Frankreich 1848 bis 1850, MEW, 8d. 7, S. 21 
haltsamen Proletarisierung. ' a) Die Bauernklasse schwankte zwischen den Polen ihres Eigentumsfanatismus, einer vagen antikapitalistischen Haltung und - in revolutionären Perioden (allerdings nicht in Deutschland) - dem Zusammenschluß mit Teilen des Kleinbürgertums und dem Proletariat gegen die „koalisierte konterrevolutionäre Bourgeoisklasse“ 2. „Die Bauern befanden sich ungefähr in derselben Lage wie die Kleinbürger, sie hatten ungefähr dieselben sozialen Forderungen zu stellen“ ${ }^{3}$. „Die demokratischen Kleinbürger, weit entfernt, für die revolutionären Proletarier die ganze Gesellschaft umwälzen zu wollen, erstreben eine Änderung der gesellschaftlichen Zustände, wodurch innen die bestehende Gesellschaft möglichst erträglich und bequem gemacht wird" ${ }^{4}$. Sie verlangen Schutzmaßnahmen gegen das Kapital und die Herstellung bürgerlicher Eigentumsverhältnisse auf dem Lande. Ihr Bewußtsein, zwischen und über den Klassen zu stehen, geht mit einer kleinmütigen Politik und ständigen politischem Schwanken einher.

5. Die seit 1860 rasch voranschreitende Akkumulation des Kapitals in Deutsch land bewirkte anders als in England keine Kapitalisierung der Landwirtschaft (mit Ausnahme Preußens). Das Gesetz, „daß die ökonomische Entwicklung die Funktionen an verschiedene Personen verteilt und der Handwerker oder Bauer, der mit seinen eigenen Produktionsmitteln produziert, ... sich entweder nach und nach in einen kleinen Kapitalisten verwandeln (wird), der auch fremde Arbeit exploitiert, oder er ... seiner Produktionsmittel verlustig gehen und in einen Lohnarbeiter verwandelt werden" 5) wird - dieses Gesetz setzte sich in Deutschland nur zögernd und vorwiegend im Sinne seiner zweiten Seite durch.

Die Bauern in Deutschland wurden zur Klasse, „welche innerhalb der Zivilisation die Barberei vertritt" ${ }^{6}$ ) - Objekt und nicht Subjekt der politischen Bewegung, passiver konservativer Boden der deutschen Gesellschaft, weder eindeutig mit der Bougeoisie noch gar mit dem Proletariat verbündet.

1.) Zum Entwicklungsgrad des Klassenantagonismus im 19. Jahrhundert und der Analyse der französischen Bauernklasse vgl. Projekt Klassenanalyse, Zur Taktik der proletarischen Partei, Berlin-West, 1971 und Joachim Bischoff, Zu einigen Grundfragen revolutionärer Taktik, Sozialistische Politik 14/15, Berlin-West, 1971, S. 110 ff.

2) Karl Marx, Die Klassenkämpfe..., e. c., S. 60

3) ebenda

4) Karl Marx, Ansprache der Zentralbehörde an den Bund, Marx/Engels-Ausgewählte Werke, Bd. 1, S. 101

5) Karl Marx, Theorien über den Mehrwert, 1. Bd., MEW 26. 1, S. 384

6) Karl Marx, Die Klassenkämpfe..., e. C., 44. Das ist natürlich nicht als ,Versagen“ der Bauern zu betrachten, sondern als Folge ihrer durch die kapitalistische Entwicklung produzierten Lage. 
6. Mit dem Übergreifen des industriellen Kapitals auf den landwirtschaftlichen Produktions- und Lebensprozeß (vor allem in Form der Auslagerung von Produktions- und Zirkulationsfunktionen sowie der Verdrängung der bäuerlichen Produktion von Gebrauchsgütern für den Eigenbedarf, vgl. vorstehender Aufsatz) und den ökonomischen und politischen Krisen der ersten Jahrzehnte des 20. Jahrhunderts gerieten die Bauern stärker in politische Bewegung, die sich an den konservativen Flügel der deutschen Bourgeoisie und die Faschisten anlehnte.

7. Auch die zügige Akkumulation des westdeutschen Kapitals nach dem 2. Weltkrieg brachte keine Kapitalisierung der traditionellen Landwirtschaft mit sich. Bis zum Anfang der 60-er Jahre unterstützen die Bauern fest die rechtsgerichteten Parteien. Ihre Lage blieb durch chronische ökonomische Rückständigkeit und zunehmende Proletarisierung gekennzeichnet.

8. Die sozioökonomische Entwicklung der Bauernklasse ${ }^{7}$ ) kristallisiert sich gegenwärtig in folgenden Tendenzen:

- selbständige traditionelle Bauernwirtschaften in einfach oder kapitalistisch warenproduzierender Form

- selbständige Bauernwirtschaften in einfach oder kapitalistisch warenproduzierender Form im Bereich der hochspezialisierter Veredelungsproduktion

- nur noch formal selbständige, einem Nahrungsmittel- oder Zirkulationskapital angeschlossene Bauernwirtschaften

- Zu- und Nebenerwerbsbetriebe

- Arbeiterbauern

Diesen hier skizzierten unterschiedlichen Produktionsweisen der einzelnen Abteilungen der Bauernklasse entsprechen unterschiedliche Bewußtseins- und Organisationsformen. Einschließlich überkommender Traditionen politischer, religiöser Art etc. sind diese Bewußtseins- und Organisationsformen in die klassenanalytische Untersuchung mit einzubeziehen.

9. Die Bauern handeln als Klasse nicht politisch selbständig, sondern sie reagieren passiv auf die Bewegung der beiden Hauptklassen. Ihr ökonomischer Niedergang, die Abhängigkeit vom Staat, ihr Selbstverständnis als Mittelklasse und ihre aufgrund ihrer Produktionsweise traditionell konservative soziale Einstellung bestimmen ihr Bewußtsein. Ihre gegenwärtige politische Radikalisierung ist eher unklar und hilflos als faschistoid.

10. Bislang haben sich die verschiedenen sozialistischen und kommunistischen Gruppen außer in abstrakt programmatischer Weise sehr wenig um die Bauernfrage gekümmert. Die Ansätze der DKP - die mit denen der DDR gegenwärtig am fortgeschrittensten sind - sollen demnächst in den „Problemen des Klassenkampfs behandelt werden. Diese und folgende

7) Es ist mit fortschreitender Auflösung der Einheitlichkeit der Klassenlage der Bauern besser, anstelle des Begriffs ,Bauernklasse' den der, ländlichen Produzenten' zu wählen. 

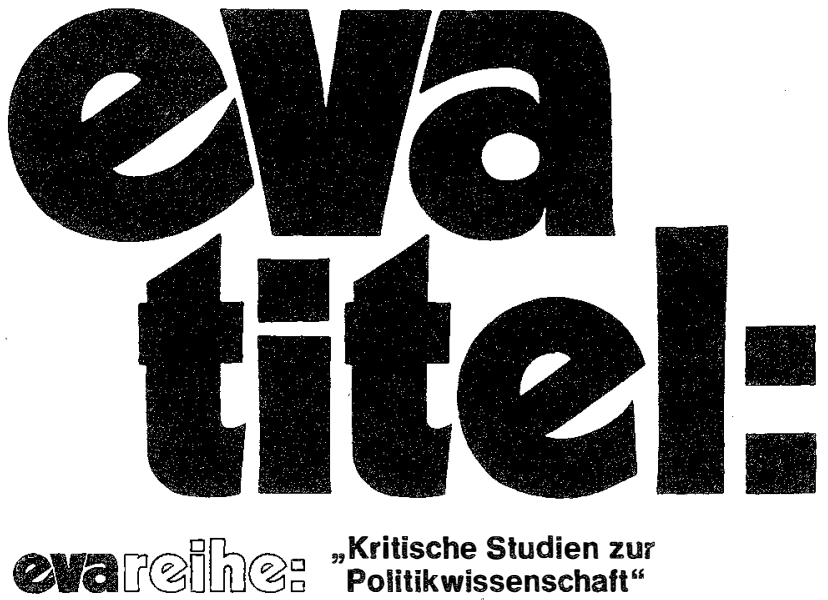

Politikwissenschaft"

Herausgegeben von Walter Euchner, Gert Schäfer und Dieter Senghaas

Dieter Senghaas

\section{Abschreckung und Frieden}

Studien zur Kritik organisierter Friedlosigkeit

1969, 320 Seiten, kartoniert 18,- DM, Leinen 26,- DM

Gisela Kress, Dieter Senghaas (Hrsg.)

\section{Politikwissenschaft}

Eine Einführung in ihre Probleme

1969, 2. Auflage 1970, 518 Seiten, kartoniert 23,- DM

Claus Koch; Dieter Senghaas (Hrsg.)

Texte zur Technokratiediskussion

Texte von André Gorz, Jean Meynaud, Wolf-Dieter Narr, Claus Offe, Dieter Senghaas u. a.

1970 , 2. Auflage 1971, 360 Seiten, kartoniert 23,- DM.

Leinen 32,- DM

Helga Grebing

Konservative gegen die Demokratie

Konservative Kritik an der Demokratie in der Bundesrepublik 1971, 466 Seiten, kartoniert 38,- DM, Leinen 48,- DM

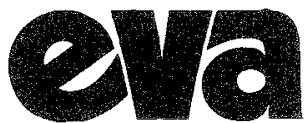

Europäische Verlagsanstalt

Frankfurt am Main 
Artikel wollen die notwendige Diskussion um die sozioökonomische Situation, politische Einschätzung der Bauern und die geeignete Taktik innen gegenüber vorantreiben. Die Diskussion muß auf die Frage zielen, welchen Stellenwert der Bauernklasse in der revolutionären Taktik der wiederentstehenden kommunistischen und Arbeiterbewegung zukommt. Das gegenwärtige Elend der Bauern ist nur in einer sozialistischen Produktionsweise aufhebbar.

Dabei darf aber nicht vergessen werden, daß das Problem der Bauern eine eher tagespolitische Brisanz hat (z. B. EWG), überdies in jede Analyse der Klassenbewegling kapitalistischer Gesellschaften einzubeziehen ist, jedoch in Ländern mit hochentwickeliem Kapitalverhältnis wie der BRD eine durchaus untergeordnete Rolle spielt.

Gerhard Armanski 